OPEN ACCESS

Edited by:

Xiaoming Jiang,

Shanghai International Studies

University, China

Reviewed by:

Natalia Bogdanova-Beglarian,

Saint Petersburg State University,

Russia

Likan Zhan,

Beijing Language and Culture University, China

*Correspondence:

Yi Shan

victorsyhz@hotmail.com

Specialty section:

This article was submitted to

Language Sciences,

a section of the journal

Frontiers in Psychology

Received: 29 May 2021 Accepted: 08 November 2021 Published: 06 December 2021

Citation:

Shan Y (2021) Investigating the Interaction Between Prosody and Pragmatics Quantitatively: A Case Study of the Chinese Discourse Marker ni zhidao ("You Know"). Front. Psychol. 12:716791. doi: 10.3389/fpsyg.2021.716791

\section{Investigating the Interaction Between Prosody and Pragmatics Quantitatively: A Case Study of the Chinese Discourse Marker ni zhidao ("You Know")}

\author{
Yi Shan ${ }^{1,2,3 *}$
}

${ }^{1}$ School of Foreign Studies, Nantong University, Nantong, China, ${ }^{2}$ College of Foreign Languages, Fujian Normal University, Fuzhou, China, ${ }^{3}$ School of Foreign Languages, Nanchang Institute of Technology, Nanchang, China

This study briefly describes the prosodic and pragmatic characteristics of the discourse marker ni zhidao ("you know") in spoken Chinese. It mainly explores the interaction between its prosody and pragmatics using instrumental methods. It is the first attempt to use acoustic and statistical analysis to examine the prosodic parameters and prosodypragmatics interaction of a Chinese discourse marker. The corpus includes 71 interview conversations totaling more than $30 \mathrm{~h}$, in which 490 discourse marker tokens of $n i$ zhidao were found. Ni zhidao mainly fulfilled four broad pragmatic functions of initiating a topic when occurring sentence-initially, of holding the floor when appearing within clauses, of marking coherence when making its presence between clauses, and of projecting attitudes and feelings when showing up sentence-finally. Drawing on the algorithm of random forest in $\mathrm{R}$, the acoustic and statistical analysis of the performance of ni zhidao in these four functions showed that its prosodic features, including duration, tempo, pre-pause, post-pause, $F_{0}$, and intensity, significantly relate to and thus imply its pragmatic functions, that the interaction between its prosody and pragmatics can be modeled statistically, and that the established pragmatics classification model based on prosody can be utilized to predict the pragmatics of ni zhidao. These findings seem to strengthen the hypothesis that prosodic variables play a role in deciphering the different pragmatic functions of ni zhidao. This study uses prosodic evidence to more objectively reveal not only the part of ni zhidao in dynamically constructing and embodying specific contexts but also its communicative functions and the underlying meta-pragmatic awareness behind it. This study breaks through the limitations of traditional discourse marker research, which mainly relies on context and discourse characteristics for subjective reasoning.

Keywords: discourse marker, prosody, pragmatic function, interaction, prosody-pragmatics model

\section{INTRODUCTION}

In essence, discourse markers (e.g., ni zhidao, you know, etc.) are linguistic items to guide the communicator's understanding of the discourse during the communicative process. They both indicate the purpose of the speaker's discourse accurately and guide the listener to understand it, thus effectively realizing the communicative intent. Related studies (e.g., Blakemore, 1987; 
Fraser, 1987; Schiffrin, 1987; Chen, 2002; He and Mo, 2002; Ran, 2002; Fang, 2005; Wu, 2005; Tanno, 2018; Rhee, 2020) have analyzed the syntactic distribution, communicative process, causes of formation, and development process of discourse markers. These researches reveal their syntactic features, discourse functions, grammaticalization, and pragmaticalization, thus deepening the academic understanding of this pragmatic phenomenon.

The pragmatic functions of discourse markers have traditionally been the focus of scholarly attention. To date, researchers (e.g., Blakemore, 1987; Fraser, 1987; Schiffrin, 1987; Chen, 2002; He and Mo, 2002; Ran, 2002; Fang, 2005; Wu, 2005; Tanno, 2018; Rhee, 2020) have primarily relied on context and syntax to examine the multiple pragmatic functions of specific discourse markers in different contexts, or to analyze how discourse markers perform certain discourse functions in specific contexts within some theoretical frameworks. These investigations need to be further developed and refined for four reasons: (1) over-relying on abstract communicative contexts for subjective reasoning; (2) lacking sufficient linguistic evidence due to investigation into only a small number of examples; (3) failing to statistically investigate the interaction between "tangible" prosody and "intangible" function of discourse markers; (4) mainly using elicited conversations as data and paying little or even no attention to spontaneous speech.

Although context can be used to identify the pragmatic functions of discourse markers, prosody can undoubtedly provide another objective and easily accessible evidence to facilitate listeners' understanding. The crucial functional load of semantically unspecified discourse markers is carried by prosodic variation (Gravano et al., 2007; Lai, 2009). However, the prosodic realization of discourse markers has received little attention (Wichmann et al., 2010) because they are more typical of spoken than written language (Brinton, 1996). Although claiming that the prosody of discourse markers performs some pragmatic functions, studies in this respect (e.g., Schegloff, 1982; Ward and Tsukahara, 2000; Ward, 2006; Gravano and Hirschberg, 2009; Buschmeier et al., 2011; Nadeu and Prieto, 2011; Nebot, 2021) fail to substantiate this prosody-pragmatics interaction with quantitative, acoustic-prosodic evidence. Realizing this neglect and failure, some linguists (e.g., Matzen, 2004; Braga and Marques, 2004; Wichmann et al., 2010; Volín et al., 2016; Didirková et al., 2018) have investigated what an analysis of prosody can reveal about the pragmatics of discourse markers. However, they neither investigated the prosodypragmatics interaction of discourse markers statistically nor modeled this interaction and then used the model to predict pragmatic functions.

Given the current state of research, this study aims to statistically examine and model the interaction between the prosody and pragmatics of the discourse marker ni zhidao in Chinese spontaneous speech based on a corpus of media interview conversations totaling more than $30 \mathrm{~h}$. To this end, six prosodic parameters, including duration, tempo, pre-pause, post-pause, $\mathrm{F}_{0}$, and intensity, were chosen, and the pragmatic functions of ni zhidao were impressionistically identified through careful listening to the audios. The hypothesis underlying this study is that prosodic variables play a role in encoding and deciphering different pragmatic functions of ni zhidao in diverse utterance positions. This hypothesis draws on the literature concerning the correlation between prosody and position on the one hand and the interaction between prosody and pragmatics on the other hand. The existent researches (e.g., Vaissière, 1983; Cai et al., 1998; Xu, 1999; Zhong et al., 2001; Hirschberg, 2002; Wu, 2002; Ward, 2004; Braga and Marques, 2004; Wang, 2011) confirmed the impact of position on $\mathrm{F}_{0}$. The discourse component at the beginning of the turn is higher in pitch, which is usually used by the speaker to take over the turn (Braga and Marques, 2004), because the speaker draws the listener's attention to the subsequent discourse by raising the pitch (Ward, 2004). The pitch of the phrase initiating a new topic is higher than that of other components in the same turn (Hirschberg, 2002). The phrase at the end of the sentence has a narrower $F_{0}$ range, a slower pitch, and a faster tempo (Hirschberg, 2002), which is the final lowering effect, that is, the sentence-final phrase carries the lowest pitch (Wang, 2011), due to compression of the pitch range during the last half-second or so of an utterance (Caspers, 1998). The aforementioned literature justifies the possibility that prosodic cues of ni zhidao could be predicted by its positions. "Different positions are responsible for subtle changes in meaning or function." (Hansen, 1997: 156) Therefore, it is reasonable to hypothesize that the prosodic cues of ni zhidao can reliably be used to classify its pragmatic functions. As has been proved in previous studies, systematic prosodic variation is functionally extrinsically motivated (Volín et al., 2016). Prosodic patterns are basically composed of different functional layers ( $\mathrm{Xu}$, 2004). The crucial functional load of discourse markers is carried by their varying prosodic patterns (Gravano et al., 2007; Lai, 2009). Prosodic parameters interact intricately to convey various communicative functions, and multi-parametric variations in $\mathrm{F}_{0}$, timing, and intensity result in basically consistent formfunction mappings (Volín et al., 2016). The prosodic elements are integrated to produce tailored discourse markers serving specifically intended communicative functions (Ward, 2006). Therefore, it is well-grounded and feasible to use prosodic clues of ni zhiao as solid evidence for its pragmatic categorization.

It is the first attempt to use acoustic and statistical analysis to probe the prosodic parameters and prosodypragmatics interaction of Chinese discourse markers. Specifically, the present research analyzed the syntactic, prosodic, and pragmatic distribution of ni zhidao, the correlation between its prosodic variables, and ultimately its prosody-pragmatics correlation through the machine learning algorithm (Random Forest in R). The syntactic, prosodic, and pragmatic analyses were designed to reveal its actual syntactic and prosodic performances statistically and its pragmatic functions intuitively for investigating the potential correlation between its prosody and pragmatics in different positions eventually. On the basis of these statistical and impressionistic analyses, the Random Forest algorithm was meant to project variations in prosody onto functional categories to find the significance of prosody to encoding and deciphering pragmatics statistically and construct a prosody-pragmatics model which can be applied to predict pragmatics, thus providing statistical evidence for 
the traditionally intuitively-claimed pragmatic functions and prosody-pragmatics interaction. As such, the investigation of ni zhidao first explored the prosody-pragmatics interface of Chinese discourse markers statistically and visually, using "visible" prosodic evidence rather than "invisible" context to more objectively reveal not only the part of $n i$ zhidao in dynamically constructing and embodying specific contexts but also its communicative functions and underlying meta-pragmatic awareness. This study, therefore, breaks through the limitations of traditional discourse marker research, which primarily relied on context and discourse characteristics for subjective reasoning, putting discourse marker studies on a more objective and scientific footing.

\section{REVIEW OF LITERATURE}

\section{Studies of Discourse Markers}

Research on discourse markers generally presents five representative perspectives: (1) Coherence model (e.g., Schiffrin, 1987, 1994, 2003; Chen, 2002; He and Mo, 2002) explores the role of discourse markers in displaying the semantic coherence between discourse segments and the discourse coherence mode; (2) Relevance model (e.g., Blakemore, 1987, 2002, 2011; Ran, 2002; Shan, 2014a; Li et al., 2018) focuses on relevant inference, studying how speakers use discourse markers to guide or restrict listeners to find relevance between discourse segments; (3) Syntactic-pragmatic model (e.g., Fraser, 1987, 1999, 2009, 2015; Akar and Öztürk, 2020) examines the syntactic features and pragmatic functions of discourse markers, arguing that the function of discourse markers is to guide the listener to correctly interpret the logical relationship between the preceding and following discourse segments; (4) Grammaticalization/pragmaticalization model (e.g., Fang, 2005; Wu, 2005; Maschler, 2009; Dong, 2010; Li, 2014; Fedriani and Sanso, 2017; Tanno, 2018; Rhee, 2020) probes into the evolution of discourse markers and the contributing factors behind this; (5) Prosody-pragmatics model (e.g., Hirschberg, 2002; Matzen, 2004; Braga and Marques, 2004; Wichmann et al., 2010; Beňuš, 2012; Abuczki, 2014; Cabarrão et al., 2015; Gonen et al., 2015; Volín et al., 2016) draws on prosody as an objective factor to identify and characterize discourse markers or as an immediate and readily accessible feature to reveal the functions of discourse markers and how people comprehend them. Some of these studies have shifted from the traditional syntactic-semantic perspective to the pragmatic-cognitive or even prosodic dimension. Some researchers (e.g., Wu, 2005; Dong, 2010; Li, 2014; Wang, 2017) have investigated Chinese discourse markers.

$\mathrm{Ni}$ zhidao among other Chinese discourse markers has relatively been under-explored, relative to discourse markers in other languages. Representative studies investigated the distinctive morphological features and attention-arousing and communication-checking functions of ni zhidao (Tao, 2003), attention-focusing, background-providing, and identification-seeking modes of ni zhidao (Liu, 2006), cognitive context-constructing, attitude-projecting, and inference-manifesting functions of ni zhidao (Shan, 2014a), discourse-constructing functions of $n i$ zhidao and the internal mechanism and external motivation for its evolution (Shan, 2014b), and the prosody of ni zhiao in different positions (Shan, 2015). These researches neither made a statistical analysis nor constructed a model by integrating position, pragmatics, and prosody. In the same vein, among studies of discourse markers in other languages, some (e.g., Blakemore, 1987; Fraser, 1987; Schiffrin, 1987; Tanno, 2018; Rhee, 2020) examined the pragmatic functions of specific discourse markers relying on context and syntax, and some mainly focused on the multifunctionality of discourse markers (e.g., Schiffrin, 1987; Brinton, 1996; Jucker and Ziv, 1998; Lenk, 1998; Erman, 2001; Aijmer, 2002) and/or their syntactic positions (e.g., Fraser, 1990; Redeker, 1991; Hansen, 1997; Schourup, 1999; Schiffrin, 2001; Halliday and Matthiessen, 2004), without mapping pragmatic functions onto syntactic positions statistically. In this research state, a statistical analysis of the utterance distributions and pragmatic roles of ni zhidao and the mapping of the former onto the latter in particular can provide new insights into the intuitively-inferred correlation between the position and pragmatics of discourse markers that "different positions are responsible for subtle changes in meaning or function" (Hansen, 1997: 156). Another factor making the study of ni zhidao unique is that Chinese belongs to a language family different from the language families of most languages investigated in the literature. Thus, more cross-linguistic comparisons will be possible and the questions of universality of some characteristics will be addressed (Volín et al., 2016).

The phonological features on discourse markers mainly discussed in the literature are pauses, phonological reduction (Schiffrin, 1987; Brinton, 1996; Tabor and Traugott, 1998), and intonation (Hirschberg and Litman, 1987, 1993; Romero-Trillo, 2015). A pause before the discourse marker is usually expected if the discourse marker occurs initially in an intonation unit, and a pause after the discourse marker is frequent, and it is hinted at by the syntactic detachment (Schiffrin, 1987) of the discourse marker and by the "comma intonation" (Tabor and Traugott, 1998: 254). The pauses on both sides of the discourse marker form a separate intonation unit, or "an independent breath unit carrying a special intonation and stress pattern" (Traugott, 1995: 60). Hirschberg and Litman (1993) found that the English well proved to be prosodically independent in only $50 \%$ of cases. Der and Marko (2010) discovered that a discourse marker is not necessarily preceded and, or followed by a pause.

Prosodic features, including accent, intonation, tone, and pauses, are significant to realizing the speaker's communicative intent (Searle, 1969). An intimate relationship exists between prosody and pragmatics (Ward, 2004). Turner (2002) classified the discourse marker you know in his corpus data into nine prosodic variants and studied their functions and distribution in various positions. Rendle-Short (2003) revealed the way the discourse marker so occurs in specific contexts with specific prosodic features and functions according to its position in the seminar. Braga and Marques (2004) identified some standard pragmatic functions for syllabification, duration, loudness, pitch height, pitch slope, and creaky voice in non-lexical sentences. 
He concluded that each of these prosodic features bears a reasonably consistent core meaning. Petukhova and Bunt (2009) have studied prosodic features such as pitch, energy, voicing, speaking rate, and segment duration. Matzen (2004) provided a descriptive analysis of the relationships between prosody and function for a discourse marker so. The results show that prosodic features distinguish the functional categories of so and that prosodic features can distinguish multifunctional tokens of so from those performing only one function. The conclusion is that prosodic features, in combination with context, are beneficial for elucidating the structure and usage of so. Wichmann et al. (2010) described the functions and prosodic realizations of of course in present-day spoken BritishEnglish and explored the relationship between prosody and grammaticalization. Their findings relate to structure, meaning and use, and prosody. In respect of construction, there is a clear preference for of course to occur in the initial position as part of the thematic material, followed by a medial position as a post-thematic marker to highlight the theme. In semantic terms, there is strong evidence of grammaticalization with more literal meanings occurring alongside subjective and intersubjective development. It was predicted that semantic change involving a loss of semantic weight favoring pragmatic meaning would also include a loss of prosodic prominence. "Prosodic choices-segmentation, accent placement, and tone choiceconvey abstract meanings that can be related only indirectly to lexical items and are motivated in part by convention, but largely by the often conflicting demands and constraints of the semantic, pragmatic and discoursal functions that discourse markers fulfill" (Wichmann et al., 2010:47). Didirková et al. (2018) found that the silent pause duration before the discourse marker, as well as the whole duration of the discourse marker itself, were used by the speaker to differentiate between the core meaning of the discourse marker and its less predictable meanings. Moreover, prosodic cues were not used redundantly, and the discourse markers did not systematically constitute a separate prosodic unit.

Much of the research on discourse markers, especially in computational linguistics, is concerned with the possible cues for disambiguation. Hirschberg and Litman $(1987,1993)$ studied now, aiming to identify its use as a "cue phrase" intonationally. According to them, prosody is the only feature that provides adequate information to distinguish between now as a cue phrase and a non-cue now. In the case of like and well, position in the sentence and the presence of a pause before or after the words in question were found helpful for the identification of discourse markers (Popescu-Belis and Zufferey, 2011). Other prosodic features have been studied in this direction too. Matzen (2004) found clear connections between the functions and prosody of so, considering length, pitch contour, sound, and position in the sentence. Stress was shown to be a diagnostic for discourse markers by Dehé and Wichmann (2010a,b). They found that the different functions of I think and I believe were distinguished by accent placement, while as discourse markers, these phrases were unstressed. The duration of the like in its various functions was explored by Gray (2010). Der and Marko (2010) attempted to identify the positional and/or acoustic properties aiding the listener in perceiving the function of a word. Beňuš (2012) looked at the relationship between the prosody and discourse/pragmatic meanings of Slovak feedback vocalization corresponding to the word no. The finding is that the function of back-channel/continuer is the most easily disambiguated by the pitch contour, duration, and other features. In contrast, other functions require more sophisticated multi-factor analyses for identifying the best disambiguating features. Van Zyl and Hanekom (2012) discovered that okay with a neutral agreement differs in prosody from okay with a reluctant agreement in the same discourse position. Gonen et al. (2015) and Hirschberg and Litman (1987, 1993) found that prosodic information facilitates the hearer distinguishing a discourse marker from its literal counterpart.

Some linguists have also studied non-English discourse markers. Abuczki (2014) found that the duration of the discourse marker was one of the two defining features distinguishing the different functions of the Hungarian discourse markers mondjuk ("let's say"), ugye ("is that so?"), and amúgy ("otherwise"). Cabarrão et al. (2015) used prosodic features to categorize discourse markers in two speech corpora of European Portuguese. Gonen et al. (2015) described the discursive characteristics of the discourse marker axshav ("now") in spoken Hebrew and explored its prosodic features. The finding is that most discourse markers had characteristic intonation contours, including a sharp decrease in the frequency inside the second syllable. It was also discovered that the duration of the performance of axshav as a discourse marker was shorter, both for the performance of the first syllable and the overall duration of the word, compared with its performance as a temporal adverbial. Volín et al. (2016) examined the prosodic forms that expressed eight pragmatic functions of the Czech discourse marker jasni ["sure," "agreed," "of course," "okay," “(al)right" or "fair enough"], including resignation, reassurance, surprise, indifference, or impatience. They proposed multi-parametric differences between jasni realizations in terms of their $\mathrm{F}_{0}$, timing, and intensity patterns, which gave rise to generally consistent form-function mappings.

As is shown in the literature above, the prosodic investigations of discourse markers either only scrutinized some prosodic variables, like accent, intonation, tone, and pauses, or merely examined certain parameters, including F0, duration, and intensity, which were used to distinguish communicative functions or disambiguate between discourse markers and their literal counterparts. However, these researches did not map prosody onto pragmatics statistically. Recent studies tried to fill this gap. The most representative, Volín et al. (2016), made a step further, exploring the form-function mappings through statistics and modeling, but they only probed a turn-initial discourse marker. The current study of ni zhidao attempts to go even further in this direction by integrating six overriding prosodic parameters into the examination of four functions of ni zhidao in four utterance positions. Such an analysis is likely to shed new light on future discourse marker studies not only in terms of a panoramic view but also with regard to cross-linguistic evidence for linguistic peculiarity and universality, thus allowing to "further 
simplify the complex form-function links in discourse markers" (Volín et al., 2016).

\section{Studies of Prosody}

As one of the intrinsic properties of discourse, prosody usually refers to three speech characteristics, including pitch, duration, and intensity (Wang, 2011). It constructs the context in which discourse intentions are interpreted, having a significant impact on the construction of discourse meaning and the interpretation of discourse functions. Studies in this respect (e.g., Li, 2002; Lin, 2002; Wu, 2002; Cao, 2003; Local and Walker, 2004; Dehé and Wichmann, 2010a,b; Sohn and Kim, 2014; Ma, 2017) have mainly explored the phonological characteristics of accent, intonation units, prosodic words, prosodic facets, and prosodic chunks based on small-sized corpora of daily speech. Only a few studies (e.g., Hirschberg and Swerts, 1998; Terken and Swerts, 2002; Xiong, 2003; Xiong and Lin, 2004) have examined the relationship between prosody and pragmatics. These studies argue that the prosodic features of discourse are primarily constrained by its communicative functions. The communicative functions of speech are, to some extent, achieved through the prosodic features.

Lucien Brown is a crucial player in prosody research successfully incorporating mainstream linguistic research on prosody into present-day pragmatics. According to Winter et al. (2013), politeness is not only expressed by honorific lexical forms commonly employed in Korean but also by speech acoustics. Brown et al. (2014) found that politeness does not merely reside in verbal markers but is co-signaled by phonetic cues. Brown and Prieto (2017) looked at how (im)politeness is communicated through prosody. They found that multiple acoustic features pattern with politeness-and impolitenessrelated meanings, including fundamental frequency (pitch), duration (length), intensity (loudness), and various aspects of voice quality, including breathiness.

These studies of prosody reveal the tone and mood of the speaker with sound waves, speech spectrum, pitch and intensity lines, and the corresponding data. They reflect the mechanisms and intentions underlying the discourse, but they fail to probe the prosody of discourse markers. The speaker's tone, attitude, and emotions can change the prosodic characteristics of discourse markers, and this change precisely reflects the speaker's mind and psychology. Discourse markers, as essential components of meta-language, are more reflective of the speaker's meta-pragmatic awareness compared with other discourse components. Examining the prosody of discourse markers can essentially reveal the discourse motivation behind the choice of discourse components. Therefore, the prosody of discourse markers should be incorporated into the study of prosody as a whole.

\section{Corpus-Based Computational Studies of the Usage of Language}

Many empirical studies of language usage based on largescale authentic corpora have been conducted across the world. These studies calculate and display information on language usages, such as lexical collocation and semantics (e.g., Gao and Wei, 2017; Gries, 2017), semantic prosody (e.g., Fujisaki and Sudo, 1971; Wei, 2006), syntax (e.g., Wang, 2003), literary texts (e.g., Fang, 2016; Liu and Wang, 2017), translation styles (e.g., Liao, 2000; Hu and Xie, 2017), academic language (e.g., Hyland and Tse, 2012; Wang and Liu, 2017; Wei, 2017), and language teaching (e.g., Wang and Zhu, 2005; He, 2010; Chen and Liang, 2017). These typical case studies reveal the internal mechanisms for, and external influences on, certain language features. The results uncover some actual language usages and the meanings, functions, and thoughts conveyed by them. Based on sufficient evidence, these results of empirical studies are sound and convincing.

Statistical analyses based on corpora represented essential breakthroughs in research methodology. Such analyses have also updated the frameworks for language description and the views on language. They have put empirical studies of language usages on the footing of combining quantitative, qualitative, and interpretative approaches. However, none of the existing statistical analyses have focused on discourse markers and their prosodic features. Prosody as an essential part of speech (Wang, 2011) and discourse markers as distinctive features of natural discourse should carry weights in the empirical studies of language usages. Phonetic techniques and computational statistics can analyze the prosody and pragmatics of discourse markers in the form of spectrograms, statistical reports, and models. Therefore, the abstract and elusive meta-pragmatic awareness can be visualized to a large extent, and the rationale for using discourse markers can be revealed more objectively.

However, "finding statistical models appropriate for dealing with the complexities of human speech is an ongoing challenge for the field of linguistics," and "this is a much-needed area of future research, which in turn would be highly beneficial to the investigations of the function and prosody of discourse markers" (Matzen, 2004).

\section{EXPERIMENTS AND METHODS}

The existing leading Chinese language corpora, including the Modern Chinese Corpus designed by the China National Language Commission, the Modern Chinese Corpus established by Peking University, the BCC Chinese Corpus of Beijing Language and Culture University, and the Media Language Corpus of China Media University, do not contain speech corpora. The Mandarin Speech Corpus for Four Major Dialects and the Media Speech Corpus are designed to fill this gap, but these two audio corpora are still under construction and cannot be used for this study. Drawing on the construction methods for these two corpora, the present study drew on ten representative media interview programs, such as PEOPLE IN THE NEWS, KE FAN QING TING, FEI CHANG DAO, MING REN MIAN DUI MIAN, QIANG QIANG SAN REN XING, etc., to create an audio corpus ${ }^{1}$ of more than $32 \mathrm{~h}$. This corpus involves 71 interview conversations and 102 speakers,

\footnotetext{
${ }^{1}$ All the interviews in the form of videos were recorded in the studios of the
} interviewing programs, where the recording levels were set and controlled by the 
consisting of 12 interviewers and 90 interviewees. An overall of 536 tokens of ni zhidao was found, among which 490 discourse marker tokens (91\%) and 46 non-discourse-marker tokens $(9 \%)$ were identified by the author and verified by an expert team of five doctors majoring in syntax and five doctors majoring in pragmatics, based on the defining characteristics of discourse markers proposed by Schiffrin (1987: 328). Of the 490 discourse marker tokens, 91 (18.6\%) were uttered by 10 interviewers, and $399(81.4 \%)$ were produced by 73 interviewees. The profile of the corpus can be shown in Tables 1, 2.

From this audio corpus, sentences ${ }^{2}$ embedding 490 discourse marker ni zhidao tokens were manually extracted as the subject of research, the corresponding audio of which totals $1 \mathrm{~h} 30^{\prime} 23^{\prime \prime}$, the related texts were manually transcribed, and the pragmatic and prosodic features were manually annotated and marked up. The annotation and mark-up of pragmatic features was the annotation and mark-up of the functional factors that affect the prosodic characteristics of discourse. It covered three dimensions: turns (the progression of turns and the types of turn-taking), discourse functions (the functions

professionals in charges of video recording. I downloaded from the official websites of the interviewing programs the videos, from which Cool edit Pro 2.1 was used to extract and save as waveform files the fractions of audios containing the DM ni zhidao. And then Praat 5304 was employed to analyze the extracted fractions of audios.

It can be seen in all of the videos that all speakers used microphones which were pinned on their clothes about 20 centimeters below their mouth, which was maybe stipulated by the working professionals in the studio.

Therefore, the difference in the recording settings (including distance to microphone and recording levels)can be overlooked in this study.

${ }^{2}$ In this research, merely the 490 ni zhidao tokens and their embedding sentences were segmented from the audios for analysis. When deciding the boundaries of the sentences embedding ni zhidao, we took into full consideration the context, the meaning of the sentences preceding and following the sentences containing $n i$ zhidao, and the indexical functions of ni zhidao.

The indexical functions of ni zhidao provide textual coordinates, which focus on "prior text vs. upcoming text: markers index their containing utterances to whatever text precedes them (proximal), or to whatever text is to follow (distal), or to both" (Schiffrin, 1987: 323).

All the sentences containing ni zhidao segmented for analysis have been checked and adjusted by five doctors majoring in syntax and five doctors majoring in pragmatics, who consulted the original audios for reference during checking and adjustment.

TABLE 1 | Profile of the interview programs.

\begin{tabular}{llcc}
\hline Media channels & Programs & $\begin{array}{c}\text { Number of Number of } \\
\text { Host (s) }\end{array}$ & $\begin{array}{c}\text { Guests } \\
\text { CCTV-1 }\end{array}$ \\
& XIAO CUI SHUO SHI & 2 & 16 \\
& PEOPLE IN THE NEWS & 1 & 4 \\
Dragon TV & KE FAN QING TING & 1 & 9 \\
& YANG LAN ONE ON ONE & 1 & 5 \\
Hunan Satellite Television & HER VILLAGE & 2 & 10 \\
Phoenix Satellite Television & LU YU YOU YUE & 1 & 9 \\
& MING REN MIAN DUI MIAN & 1 & 9 \\
& QIANG QIANG SAN REN XING & 1 & 11 \\
& FEI CHANG DAO & 1 & 4 \\
MSN & XING YUE DUI HUA & 1 & 13 \\
Total & 10 & 12 & 90
\end{tabular}

of turn-composing and non-turn-composing linguistic units), and paralinguistic information (mood, attitude, etc.) (Xiong, 2003). In the annotation and mark-up of prosody, Praat speech analysis software was used to characterize prosodic parameters, such as duration, tempo, pause (speech break-off), pitch, and intensity. On this basis, all discourse marker tokens of ni zhidao were identified and extracted from the corpus and then classified according to their discourse positions. Subsequently, the discourse functions and prosodic features of all ni zhidao tokens were examined in detail.

"The courts, education, police, social services, medicine, business meetings, and mass media have all been major areas of institutional talk research during the past 20 years" (Heritage, 1997: 106-107). The data of this research was selected from one distinct category of institutional talk, interview speech, which is institutional by nature and thus relatively formal. The institutional talk takes place in social institutions of various walks of life. The defining characteristics of institutional talk lie in the fact that the interactions in institutional settings are conducted between laypeople and representatives of public institutions. Thus, the institutional talk features the following attributes: the interaction targets goals tied to relevant identities in institutional organizations; the interaction exerts particular constraints on allowable contributions to the business at hand; the interaction involves special inferences particular to specific contexts (Heritage, 1997: 106). As a result, the activities of the conversationalists tend to be strongly influenced by such restrictions of goal orientation, special constraints on contributions, and special inferences. In this respect, there is little "stylistic" difference between different speakers in the data.

In addition, since all of the conversations from which the data was extracted are media interviews, the participants fall into two groups according to their roles: hosts/interviewers and guests/interviewees. The hosts function as the monitors and controllers of the talk flow. They "despite differences in style are all adept at managing outrage, encouraging the telling of secrets, cooling off the proceedings if they threaten the continuity of the show, shutting off boring guests, putting people on the spot, summing up with clichés and platitudes complex situations making the audience feel comfortable witnessing private matters" (Abt and Seesholtz, 1994: 211). They have to elicit the guests' account of personal experiences and viewpoints on specific topics by establishing enough rapport with the guests so that discourse is facilitated instead of being hindered. The guests, under the hosts' elicitation, narrate their personal experiences in a vernacular style due to the stressful situations of interviews and their emotional display. So, the stylistic differences that should be considered are speaker roles (interviewers vs. interviewees) and speakers' emotional states. Besides, speaking styles caused by the speakers' physiological variations ought to be considered. These factors will be discussed in section "Results and Discussion."

Combining computational statistics and modeling, modern speech technology, and discourse analysis, we conducted an empirical study of the actual usage of ni zhidao. The specific procedures of the experiments involved the analysis 
TABLE 2 | Profile of the audio data of 71 interview conversations.

\begin{tabular}{|c|c|c|c|c|c|}
\hline Programs & File name & Duration & Overall ni zhidao tokens & $\begin{array}{l}\text { Tokens by } \\
\text { interviewer }\end{array}$ & $\begin{array}{l}\text { Tokens by } \\
\text { interviewee }\end{array}$ \\
\hline \multirow[t]{9}{*}{ XIAO CUI SHUO SHI } & Wav.1 & $9^{\prime} 02^{\prime \prime}$ & 2 & $\begin{array}{l}2 \text { by interviewer } 1 \\
0 \text { by interviewer } 2\end{array}$ & 0 by interviewee 1 \\
\hline & Wav.2 & $14^{\prime} 55^{\prime \prime}$ & 2 & $\begin{array}{l}0 \text { by interviewer } 1 \\
0 \text { by interviewer } 2\end{array}$ & 0 by interviewee 2 \\
\hline & Wav.3 & $17^{\prime} 48^{\prime \prime}$ & 6 & $\begin{array}{l}0 \text { by interviewer } 1 \\
0 \text { by interviewer } 2\end{array}$ & $\begin{array}{l}2 \text { by interviewee } 3 \\
2 \text { by interviewee } 4\end{array}$ \\
\hline & Wav.5 & $22^{\prime} 54^{\prime \prime}$ & 4 & $\begin{array}{l}0 \text { by interviewer } 1 \\
0 \text { by interviewer } 2\end{array}$ & $\begin{array}{l}2 \text { by interviewee } 6 \\
2 \text { by interviewee } 7\end{array}$ \\
\hline & Wav.6 & $23^{\prime} 30^{\prime \prime}$ & 6 & $\begin{array}{l}6 \text { by interviewer } 1 \\
0 \text { by interviewer } 2\end{array}$ & 0 by interviewee 8 \\
\hline & Wav.7 & $11^{\prime} 57^{\prime \prime}$ & 5 & $\begin{array}{l}2 \text { by interviewer } 1 \\
0 \text { by interviewer } 2\end{array}$ & 3 by interviewee 9 \\
\hline & Wav.10 & $22^{\prime} 44^{\prime \prime}$ & 12 & $\begin{array}{l}0 \text { by interviewer } 1 \\
0 \text { by interviewer } 2\end{array}$ & 12 by interviewee 13 \\
\hline & Wav.11 & $18^{\prime} 35^{\prime \prime}$ & 4 & $\begin{array}{l}0 \text { by interviewer } 1 \\
2 \text { by interviewer } 2\end{array}$ & 2 by interviewee 14 \\
\hline & Wav.12 & $19^{\prime} 56^{\prime \prime}$ & 4 & $\begin{array}{l}4 \text { by interviewer } 1 \\
0 \text { by interviewer } 2\end{array}$ & 0 by interviewee 15 \\
\hline PEOPLE IN THE NEWS & Wav.18 & $20^{\prime} 39^{\prime \prime}$ & 8 & 2 by interviewer 3 & $\begin{array}{l}6 \text { by interviewee } 16 \\
0 \text { by interviewee } 17 \\
0 \text { by interviewee } 18\end{array}$ \\
\hline YANG LAN ONE ON ONE & Wav.13 & $10^{\prime} 44^{\prime \prime}$ & 3 & 3 by interviewer 4 & 0 by interviewee 19 \\
\hline & Wav.22 & $13^{\prime} 59^{\prime \prime}$ & 6 & 0 by interviewer 5 & 6 by interviewee 27 \\
\hline & Wav.23 & $5^{\prime} 46^{\prime \prime}$ & 5 & 2 by interviewer 5 & $\begin{array}{l}3 \text { by interviewee } 28 \\
0 \text { by interviewee } 29\end{array}$ \\
\hline & Wav.24 & $18^{\prime} 23^{\prime \prime}$ & 7 & 0 by interviewer 5 & 7 by interviewee 30 \\
\hline & Wav.25 & $27^{\prime} 52^{\prime \prime}$ & 9 & 0 by interviewer 5 & 9 by interviewee 31 \\
\hline \multirow[t]{3}{*}{ FEI CHANG DAO } & Wav.26 & $20^{\prime} 23^{\prime \prime}$ & 10 & 0 by interviewer 6 & 10 by interviewee 32 \\
\hline & Wav.27 & $17^{\prime} 52^{\prime \prime}$ & 6 & 0 by interviewer 6 & 6 by interviewee 33 \\
\hline & Wav.28 & $1 \mathrm{~h} 8^{\prime} 11^{\prime \prime}$ & 32 & 0 by interviewer 6 & 32 by interviewee 34 \\
\hline \multirow[t]{7}{*}{ LU YU YOU YUE } & Wav.29 & $21^{\prime} 20^{\prime \prime}$ & 7 & 0 by interviewer 7 & 7 by interviewee 35 \\
\hline & Wav.30 & $21^{\prime} 23^{\prime \prime}$ & 6 & 0 by interviewer 7 & 6 by interviewee 36 \\
\hline & Wav.31 & $9^{\prime} 15^{\prime \prime}$ & 4 & 0 by interviewer 7 & 4 by interviewee 37 \\
\hline & Wav.32 & $31^{\prime} 10^{\prime \prime}$ & 4 & 0 by interviewer 7 & 4 by interviewee 38 \\
\hline & Wav.33 & $29^{\prime} 07^{\prime \prime}$ & 9 & 0 by interviewer 7 & 9 by interviewee 39 \\
\hline & Wav.34 & $32^{\prime} 07^{\prime \prime}$ & 10 & 0 by interviewer 7 & 10 by interviewee 40 \\
\hline & Wav.35 & $1 \mathrm{~h} 35^{\prime} 18^{\prime \prime}$ & 38 & 2 by interviewer 7 & 36 by interviewee 41 \\
\hline \multirow[t]{3}{*}{ QIANG QIANG SAN REN XING } & Wav.36 & $21^{\prime} 23^{\prime \prime}$ & 6 & 0 by interviewer 8 & $\begin{array}{l}6 \text { by interviewee } 42 \\
0 \text { by interviewee } 43\end{array}$ \\
\hline & Wav.37 & $21^{\prime} 22^{\prime \prime}$ & 5 & 0 by interviewer 8 & $\begin{array}{l}5 \text { by interviewee } 44 \\
0 \text { by interviewee } 45\end{array}$ \\
\hline & Wav.38 & $21^{\prime} 08^{\prime \prime}$ & 6 & 4 by interviewer 8 & $\begin{array}{l}2 \text { by interviewee } 46 \\
0 \text { by interviewee } 47\end{array}$ \\
\hline
\end{tabular}


TABLE 2 | Continued

\begin{tabular}{|c|c|c|c|c|c|}
\hline Programs & File name & Duration & Overall ni zhidao tokens & $\begin{array}{l}\text { Tokens by } \\
\text { interviewer }\end{array}$ & $\begin{array}{l}\text { Tokens by } \\
\text { interviewee }\end{array}$ \\
\hline & Wav.39 & $3^{\prime} 06^{\prime \prime}$ & 1 & 1 by interviewer 8 & $\begin{array}{l}1 \text { by interviewee } 48 \\
0 \text { by interviewee } 49\end{array}$ \\
\hline & Wav.40 & $22^{\prime} 15^{\prime \prime}$ & 12 & 8 by interviewer 8 & $\begin{array}{l}2 \text { by interviewee } 50 \\
2 \text { by interviewee } 51\end{array}$ \\
\hline & Wav.41 & $21^{\prime} 30^{\prime \prime}$ & 4 & 3 by interviewer 8 & $\begin{array}{l}1 \text { by interviewee } 52 \\
0 \text { by interviewee } 53\end{array}$ \\
\hline & Wav.42 & $22^{\prime} 01^{\prime \prime}$ & 5 & 0 by interviewer 8 & $\begin{array}{l}5 \text { by interviewee } 54 \\
0 \text { by interviewee } 55\end{array}$ \\
\hline & Wav.43 & $8^{\prime} 08^{\prime \prime}$ & 4 & 1 by interviewer 8 & $\begin{array}{l}3 \text { by interviewee } 56 \\
0 \text { by interviewee } 57\end{array}$ \\
\hline & Wav.44 & $21^{\prime} 07^{\prime \prime}$ & 8 & 5 by interviewer 8 & $\begin{array}{l}3 \text { by interviewee } 58 \\
0 \text { by interviewee } 59\end{array}$ \\
\hline & Wav.45 & $20^{\prime} 53^{\prime \prime}$ & 9 & 4 by interviewer 8 & $\begin{array}{l}3 \text { by interviewee } 60 \\
2 \text { by interviewee } 61\end{array}$ \\
\hline \multirow[t]{8}{*}{ MING REN MIAN DUI MIAN } & Wav.46 & $23^{\prime} 32^{\prime \prime}$ & 3 & 1 by interviewer 9 & 2 by interviewee 62 \\
\hline & Wav.47 & $23^{\prime} 09^{\prime \prime}$ & 6 & 0 by interviewer 9 & 6 by interviewee 63 \\
\hline & Wav.48 & $23^{\prime} 09^{\prime \prime}$ & 5 & 0 by interviewer 9 & 5 by interviewee 64 \\
\hline & Wav.49 & $23^{\prime} 51^{\prime \prime}$ & 3 & 0 by interviewer 9 & 3 by interviewee 65 \\
\hline & Wav.50 & $24^{\prime} 44^{\prime \prime}$ & 4 & 0 by interviewer 9 & 4 by interviewee 66 \\
\hline & Wav.51 & $24^{\prime} 19^{\prime \prime}$ & 6 & 0 by interviewer 9 & 6 by interviewee 67 \\
\hline & Wav.52 & $24^{\prime} 50^{\prime \prime}$ & 4 & 1 by interviewer 9 & 3 by interviewee 68 \\
\hline & Wav.53 & $16^{\prime} 31^{\prime \prime}$ & 5 & 0 by interviewer 9 & 5 by interviewee 69 \\
\hline \multirow[t]{7}{*}{ HER VILLAGE } & Wav.54 & $20^{\prime} 34^{\prime \prime}$ & 7 & $\begin{array}{l}5 \text { by interviewer } 10 \\
0 \text { by interviewer } 11\end{array}$ & 2 by interviewee 70 \\
\hline & Wav.55 & $18^{\prime} 22^{\prime \prime}$ & 9 & $\begin{array}{l}1 \text { by interviewer } 10 \\
0 \text { by interviewer } 11\end{array}$ & 5 by interviewee 71 \\
\hline & Wav.56 & $38^{\prime} 14^{\prime \prime}$ & 12 & $\begin{array}{l}4 \text { by interviewer } 10 \\
0 \text { by interviewer } 11\end{array}$ & 8 by interviewee 72 \\
\hline & Wav.57 & $19^{\prime} 28^{\prime \prime}$ & 6 & $\begin{array}{l}2 \text { by interviewer } 10 \\
0 \text { by interviewer } 11\end{array}$ & 4 by interviewee 73 \\
\hline & Wav.58 & $27^{\prime} 34^{\prime \prime}$ & 9 & $\begin{array}{l}1 \text { by interviewer } 10 \\
0 \text { by interviewer } 11\end{array}$ & $\begin{array}{l}3 \text { by interviewee } 74 \\
5 \text { by interviewee } 75\end{array}$ \\
\hline & Wav.59 & $18^{\prime} 33^{\prime \prime}$ & 8 & $\begin{array}{l}0 \text { by interviewer } 10 \\
0 \text { by interviewer } 11\end{array}$ & 8 by interviewee 76 \\
\hline & Wav.60 & $19^{\prime} 47^{\prime \prime}$ & 7 & $\begin{array}{l}4 \text { by interviewer } 10 \\
0 \text { by interviewer } 11\end{array}$ & $\begin{array}{l}2 \text { by interviewee } 77 \\
1 \text { by interviewee } 78\end{array}$ \\
\hline \multirow[t]{11}{*}{ XING YUE DUI HUA } & Wav.61 & $4^{\prime} 52^{\prime \prime}$ & 2 & 0 by interviewer 12 & 2 by interviewee 79 \\
\hline & Wav.62 & $9^{\prime} 58^{\prime \prime}$ & 6 & 0 by interviewer 12 & 6 by interviewee 80 \\
\hline & Wav.63 & $4^{\prime} 57^{\prime \prime}$ & 3 & 0 by interviewer 12 & 3 by interviewee 81 \\
\hline & Wav.64 & $7^{\prime} 35^{\prime \prime}$ & 7 & 1 by interviewer 12 & 6 by interviewee 82 \\
\hline & Wav.65 & $7^{\prime} 15^{\prime \prime}$ & 6 & 0 by interviewer 12 & 6 by interviewee 83 \\
\hline & Wav.66 & $4^{\prime} 59^{\prime \prime}$ & 3 & 0 by interviewer 12 & 3 by interviewee 84 \\
\hline & Wav.67 & $9^{\prime} 45^{\prime \prime}$ & 5 & 0 by interviewer 12 & 5 by interviewee 85 \\
\hline & Wav.68 & $7^{\prime} 33^{\prime \prime}$ & 4 & 0 by interviewer 12 & 4 by interviewee 86 \\
\hline & Wav.69 & $8^{\prime} 07^{\prime \prime}$ & 5 & 0 by interviewer 12 & 5 by interviewee 87 \\
\hline & Wav.70 & $4^{\prime} 57^{\prime \prime}$ & 3 & 1 by interviewer 12 & 2 by interviewee 88 \\
\hline & Wav.71 & $18^{\prime} 36^{\prime \prime}$ & 8 & 0 by interviewer 12 & $\begin{array}{l}4 \text { by interviewee } 89 \\
4 \text { by interviewee } 90\end{array}$ \\
\hline Total & 71 wave files & 32 h $2^{\prime} 47^{\prime \prime}$ & 490 & 91 by 10 interviewers & 399 by $\mathbf{7 3}$ interviewees \\
\hline
\end{tabular}

of its prosodic parameters, the investigation of its pragmatic functions, and the examination of the interaction between its prosody and pragmatics.

In analyzing the prosody of ni zhidao, we drew on Praat speech technology to visualize and label the prosodic features and output results (see Figure 1).

In this process, we first inputted the wave files into Praat and obtained the sound spectrograms. In these spectrograms, we separated ni zhidao from the rest of its embedding sentence 


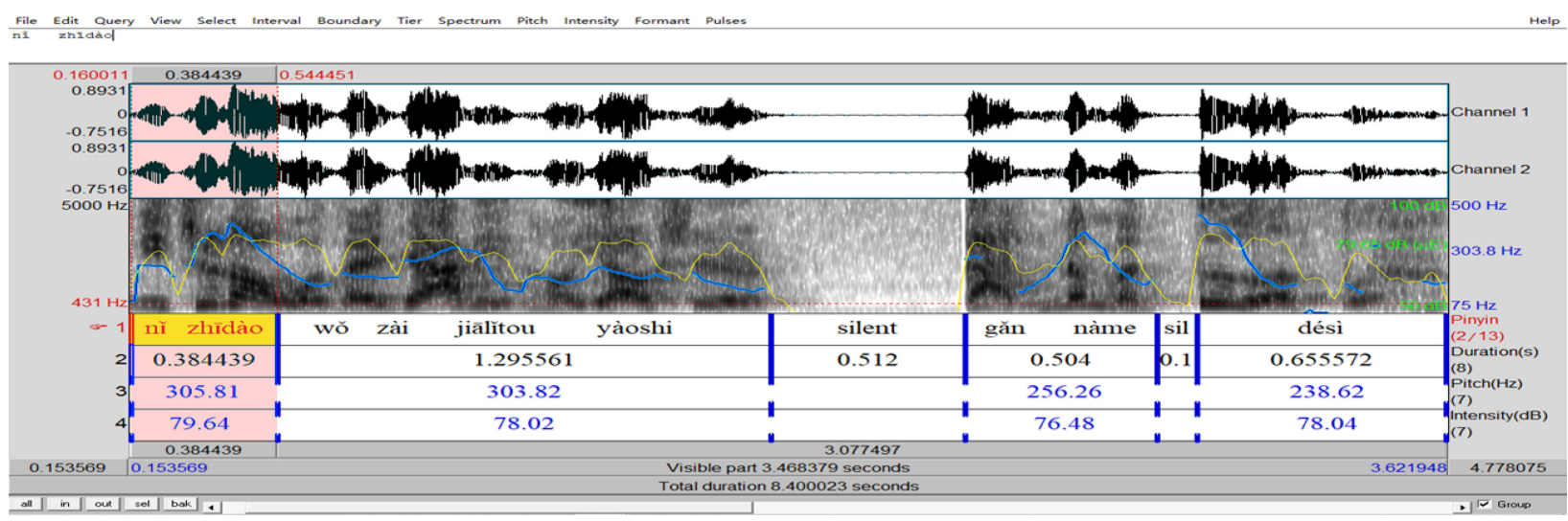

FIGURE 1 | Prosodic features of ni zhidao manifested through Praat.

by acoustically determining its onset and offset $^{3}$. Then we added scripts in Chinese pinyin and duration (and pauses, if they did occur) manually. Based on duration, we got the tempo ${ }^{4}$ values. After that, we used Praat "Pitch" and "Intensity" functions (shown at the top of Figure 1) to collect the values of $\mathrm{F}_{0}$ and intensity semi-automatically. In these functions, there are sub-functions, including "Pitch listing," "Get pitch," "Get minimum pitch," and "Get maximum pitch," which can provide the corresponding value (s) of the selected audio part. "Pitch listing" is used to obtain a list of pitches corresponding to any point of time during the duration of ni zhidao in time sequence in a new automatically pop-up window; "Get pitch" is used to show the mean pitch of ni zhidao during its duration in a new automatically pop-up window; "Get minimum pitch" is used to display the minimum pitch of ni zhidao over its duration in a new automatically pop-up window; "Get maximum pitch" is used to get the maximum pitch of ni zhidao over its duration in a new automatically pop-up window. In the same vein, the mean, minimum, and maximum intensity of ni zhidao can be obtained through "Intensity listing," "Get intensity," "Get minimum intensity," and "Get maximum intensity" functions. Besides, once ni zhidao and the pause before and after it is selected, the value of its duration and pre-pause and post-pause will automatically be shown at the bottom panel of the Praat window. All values of the collected prosodic parameters were checked and adjusted by three doctoral students majoring in phonetics and their supervisor. Finally, based on the values obtained, we used the $\mathrm{R}$ boxplot to plot the distribution of prosody (see Figure 2).

In the pragmatic investigation of ni zhidao, we relied not merely on context, Schiffrin (1987), and Matzen (2004) as the main determinants of pragmatic functions (see Figures 6-8), but

\footnotetext{
${ }^{3}$ As with the determination of the onset and offset of ni zhidao, we drew on acoustic recognition, as well as the characteristics of the sound spectrogram, to determine the boundary of phonemes and/or syllables.

${ }^{4}$ There are, generally, two ways of measuring tempo: calculating the mean duration of syllables contained in an sentence, or calculating the number of syllables uttered in a second (Cao, 2003; Li, 2006). Considering that Chinese is a "syllable-timed" (Keller and Zellner, 1996) language, the present study adopts the first approach.
}

on position and prosody as supplementary references as well. Subsequently, we invited four doctors of pragmatics to verify the pragmatic functions inferred.

In terms of the correlation of prosody and pragmatics of $n i$ zhidao, we used the random forest in $\mathrm{R}$ to construct a pragmatics classification model based on prosody (see Figure 11) to find out the importance of prosody to the performance of pragmatic functions (see Figure 12), and then to use the model constructed to predict pragmatic functions. Subsequently, based on the statistical evidence, we objectively interpreted the interaction between the prosody and pragmatics of ni zhidao.

This corpus-based research used prosodic evidence to objectively reveal not merely the role of ni zhidao in dynamically constructing and embodying specific contexts but also its communicative functions and the meta-pragmatic awareness underlying it. Such a study can, to a large extent, break through the limitations of traditional discourse marker research, which mainly relies on context and discourse characteristics for subjective and intuitive reasoning. Therefore, the method for discourse marker studies can be made more rigorous, the scope

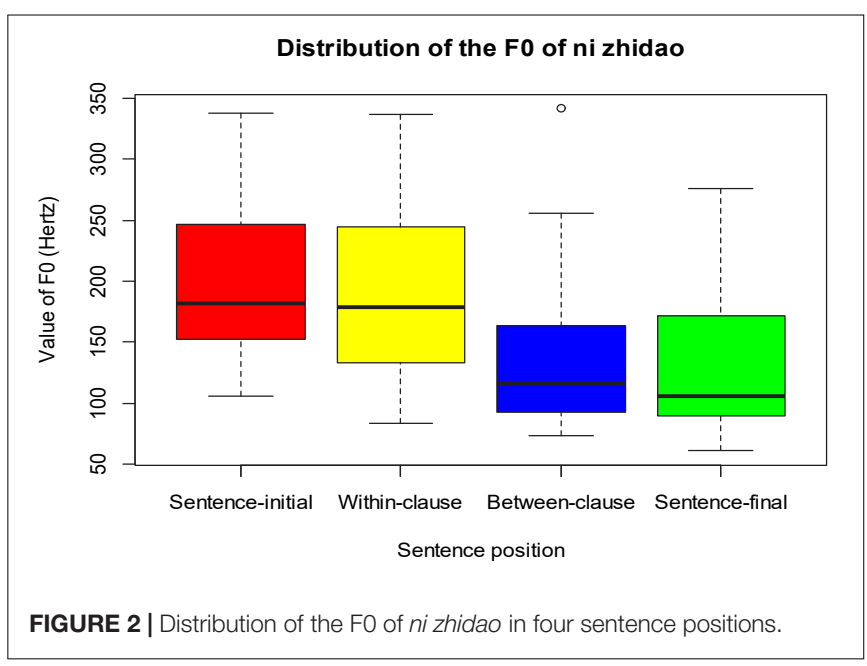


of research can be made more extensive, and the findings can be made sounder.

\section{RESULTS AND DISCUSSION}

\section{Sentence Positions of ni zhidao}

It was found that the 490 tokens of ni zhidao were used in four sentence positions: 50 at the beginning of sentences, 108 within clauses, 170 between clauses ${ }^{5}$, and 162 at the end of sentences. Figure 3 illustrates this distribution.

As Figure 3 shows, most ni zhidao tokens were used in the middle (within-clause and between-clause) and at the end of sentences. This discovery indicates that the findings of some studies (e.g., Schiffrin, 1987; Fraser, 1990; Hansen, 1997; Schourup, 1999) need to be updated, which advocate that occurring at the beginning of a sentence (initiality) is one of the defining features of discourse markers.

\section{Distribution of Prosodic Parameters of ni zhidao}

Figure 4 summarizes the values of ni zhidao's prosodic parameters, including their minimum and maximum values,

${ }^{5}$ In this paper, "clause" merely refers to that within the same sentence where each token of ni zhidao is embedded. So, between-clause tokens only refer to those inserted between two clauses embedded in the same sentences. Sentence-initial tokens and sentence-final tokens should not be regarded as between-clause, for the former are merely pragmatically indexed to the clause(s) following them, and the latter are only pragmatically indexed to the clause(s) preceding them. mean values, median values, and 1 st and 3 rd quartile values, in the dataset as a whole. When occurring in different sentence positions, ni zhidao displays different ranges of values regarding duration, tempo, pre-pause, post-pause, $\mathrm{F}_{0}$, and intensity, as is illustrated in Figure 5.

Table 3 shows the mean values of $n i$ zhidao's prosodic parameters in four sentence positions.

Figure 5 and Table 3 show specific correlations between the prosodic parameters and sentence distribution of ni zhidao. Clearly, from the sentence-initial to sentence-final positions, the duration of ni zhidao shortened gradually, its tempo sped up gradually, and its $\mathrm{F}_{0}$ and intensity decreased gradually; sentence-initial ni zhidao had the most extended duration, the slowest tempo, the highest $\mathrm{F}_{0}$, and the most vigorous intensity. These findings confirm some existing findings: in general, $\mathrm{F}_{0}$ is positively correlated with duration (Cai et al., 1998; Xu, 1999; Zhong et al., 2001; Tao, 2001); higher pitch, more vigorous intensity, and longer duration generally focus on the same discourse component (Vaissière, 1983); the discourse component at the beginning of the turn is higher in pitch, which is usually used by the speaker to grab or take over the turn (Braga and Marques, 2004); the speaker draws the listener's attention to the subsequent discourse by raising the pitch (Ward, 2004); the pitch of the phrase initiating a new topic is higher than that of other components in the same turn (Hirschberg, 2002); intensity increases or decreases automatically as $\mathrm{F}_{0}$ increases or decreases $(\mathrm{Wu}, 2002)$; the phrase at the end of the sentence has a narrower $\mathrm{F}_{0}$ range, lower pitch, and faster tempo (Hirschberg, 2002); there is the

\section{Distribution of ni zhidao in four sentence positions}

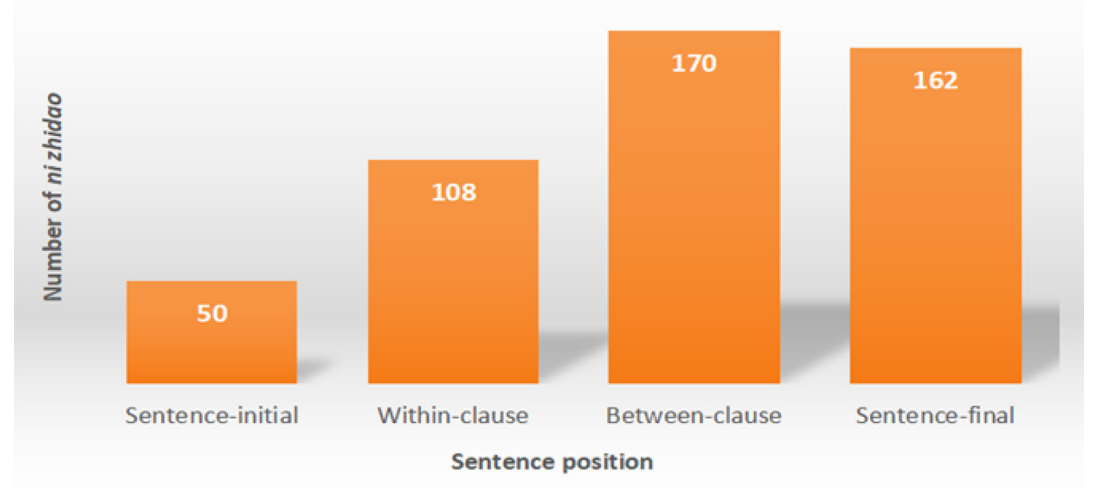

FIGURE 3 | Distribution of ni zhidao in four sentence positions.

\begin{tabular}{|c|c|c|c|c|c|}
\hline Duration & Tempo & Pre.pause & Post.pause & FO & Intensity \\
\hline$: 0.1230$ & $: 0.0310$ & $: 0.0000$ & $: 0.00000$ & $: 61.03$ & $: 51.42$ \\
\hline lst Qu.:0.3070 & lst Qu.:0.0920 & lst Qu.:0.0000 & lst Qu.:0.00 & 1st Qu.: 97.12 & 1st Qu.: 70.21 \\
\hline Median : 0.3850 & Median :0.1130 & Median : 0.0000 & Median :0.00000 & Median : 134.24 & Median : 76.2 \\
\hline$: 0.4081$ & $: 0.1161$ & $: 0.2589$ & $: 0.09401$ & $: 153.28$ & $: 74.38$ \\
\hline 3rd Qu.: 0.4930 & 3rd Qu.:0.1370 & $3 \mathrm{rd}$ Qu.: 0.4480 & $3 \mathrm{rd} \mathrm{Qu.:0.08200}$ & 3rd Qu.: 186.52 & 3rd Qu.: 79.59 \\
\hline$: 0.7770$ & $: 0.2080$ & $: 1.6010$ & $: 0.84700$ & $: 341.28$ & $: 89.67$ \\
\hline
\end{tabular}

FIGURE 4 | Profile of values of prosodic parameters of ni zhidao in four sentence positions. 
effect of final lowering, that is, the phrase at the end of the sentence displays the lowest pitch (Wang, 2011). The package "PerformanceAnalytics" in $\mathrm{R}$ was used to demonstrate the correlations between the six prosodic variables of ni zhidao, as is illustrated in Figure 6.

The matrix in Figure 6 makes the binary variable correlation well pronounced. The diagonal shows the histograms of the data for the six prosodic variables. The upper right cells (above the diagonal) show the correlation coefficients ${ }^{6}$ for any two variables

${ }^{6}$ Correlation coefficient: A positive correlation coefficient indicates a positive relationship between variables; a negative correlation coefficient indicates a negative relationship between variables; the closer the data is to 1 or -1 , the greater the correlation between variables is.

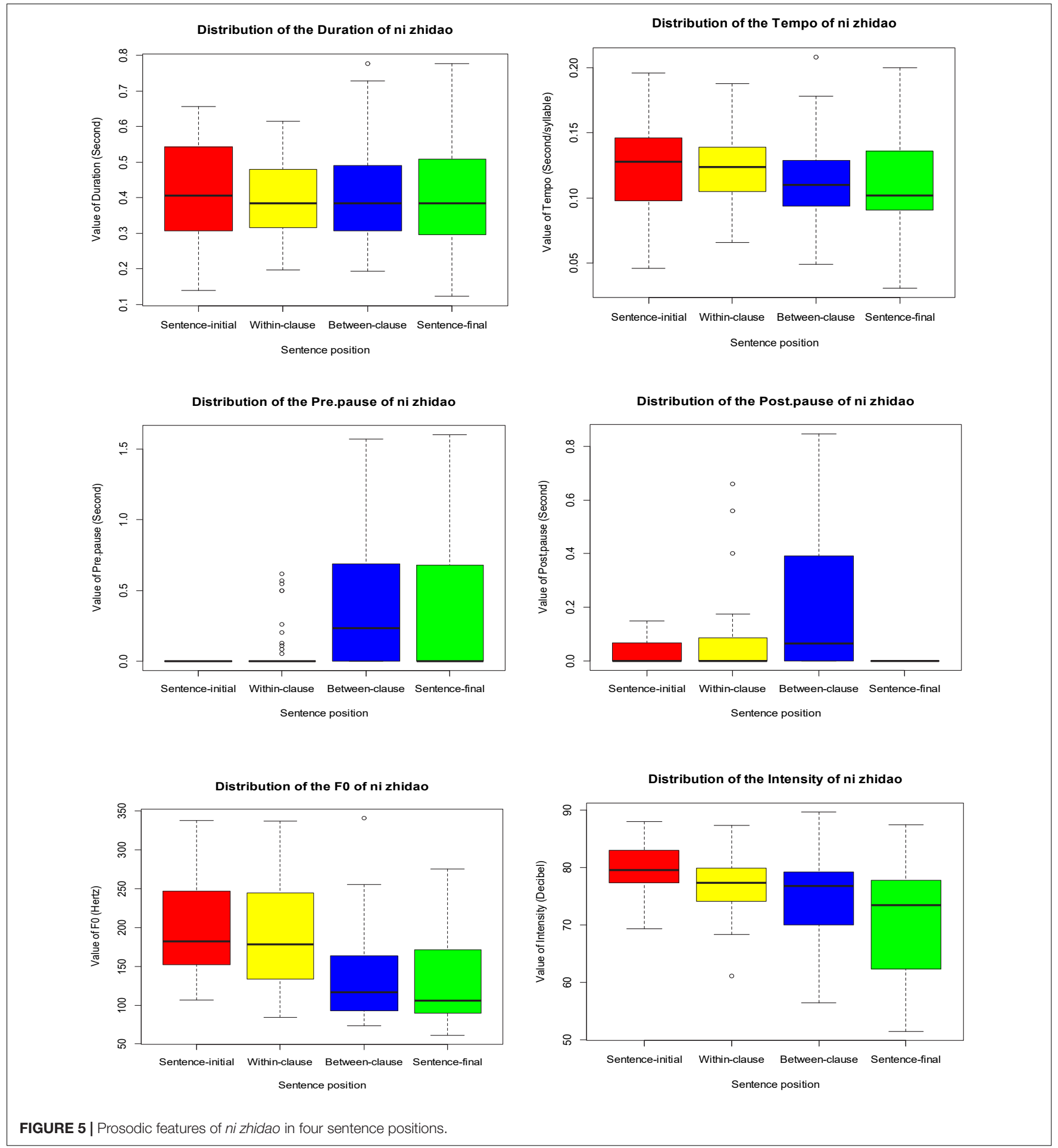


TABLE 3 | Mean values of prosodic parameters of ni zhidao in four sentence positions.

\begin{tabular}{lcccc}
\hline Prosodic features & \multicolumn{4}{c}{ Positions } \\
\cline { 2 - 5 } & $\begin{array}{c}\text { Sentence- } \\
\text { initial }\end{array}$ & $\begin{array}{c}\text { Within- } \\
\text { clause }\end{array}$ & $\begin{array}{c}\text { Between- } \\
\text { clause }\end{array}$ & $\begin{array}{c}\text { Sentence- } \\
\text { final }\end{array}$ \\
\hline Mean pre-pause (second) & - & 0.093 & 0.371 & 0.328 \\
Mean post-pause (second) & 0.194 & 0.082 & 0.261 & - \\
Mean duration (second) & 0.384 & 0.372 & 0.360 & 0.336 \\
Mean tempo (second/syllable) & 0.128 & 0.124 & 0.120 & 0.112 \\
Mean $\mathrm{F}_{0}(\mathrm{~Hz})$ & 196.733 & 185.053 & 142.822 & 131.872 \\
Mean intensity (dB) & 79.041 & 76.920 & 75.033 & 70.300 \\
\hline
\end{tabular}

and significance levels ${ }^{7}$. The lower left cells (below the diagonal) show the scatterplot of any two variables with the fitted lines ${ }^{8}$.

The scatterplot and fitted lines, correlation coefficients, and significance levels all show that there is a significant correlation between any two of the five variables, including duration,

${ }^{7}$ Level of significance: the higher the number of asterisks * is, the more significant the correlation between variables is. The absence of an asterisk * indicates a weak correlation.

${ }^{8}$ Fitted line: The closer the distribution is to the fitted line, the more significant the correlation between two variables. tempo, pre-pause, $F_{0}$, and intensity and that there is no significant correlation between post-pause and the four variables of intensity, duration, tempo, and pre-pause, and post-pause is only significantly correlated with $\mathrm{F}_{0}$.

As is statistically proved in Figure 6, the $\mathrm{F}_{0}$ of $n i$ zhidao is positively correlated with its duration, tempo, and intensity, and negatively correlated with its pre-pause and post-pause; the existent studies (e.g., Vaissière, 1983; Cai et al., 1998; Xu, 1999; Zhong et al., 2001; Hirschberg, 2002; Wu, 2002; Ward, 2004; Braga and Marques, 2004; Wang, 2011) confirms the impact of intensity, duration (and tempo), position, and final lowering effect on $\mathrm{F}_{0}$. Therefore, both the statistical evidence and the findings in the literature can somehow explain the wide range of the mean values of ni zhidao from 61.03 to $341.28 \mathrm{~Hz}$. Ni zhidao's pitch contours of greatly varying ranges revealed in the acoustic experiment, such $75.30-105.17 \mathrm{~Hz}, 80.91-99.46 \mathrm{~Hz}$, $123.85-192.53 \mathrm{~Hz}, 146.63-236.91 \mathrm{~Hz}, 209.16-266.06 \mathrm{~Hz}, 185.54-$ $277.47 \mathrm{~Hz}, 182.71-311.54 \mathrm{~Hz}, 217.89-397.14 \mathrm{~Hz}, 120.52-$ $407.84 \mathrm{~Hz}$, etc., also justify this wide range to some extent. There is a rich linguistic tradition characterizing variation in overall pitch contour in many different ways: syntactic mood, speaker attitudes, and speaker beliefs (Bolinger, 1989). Some inherent meaning has often been sought in particular contours-often modulated by context (Liberman and Sag, 1974).

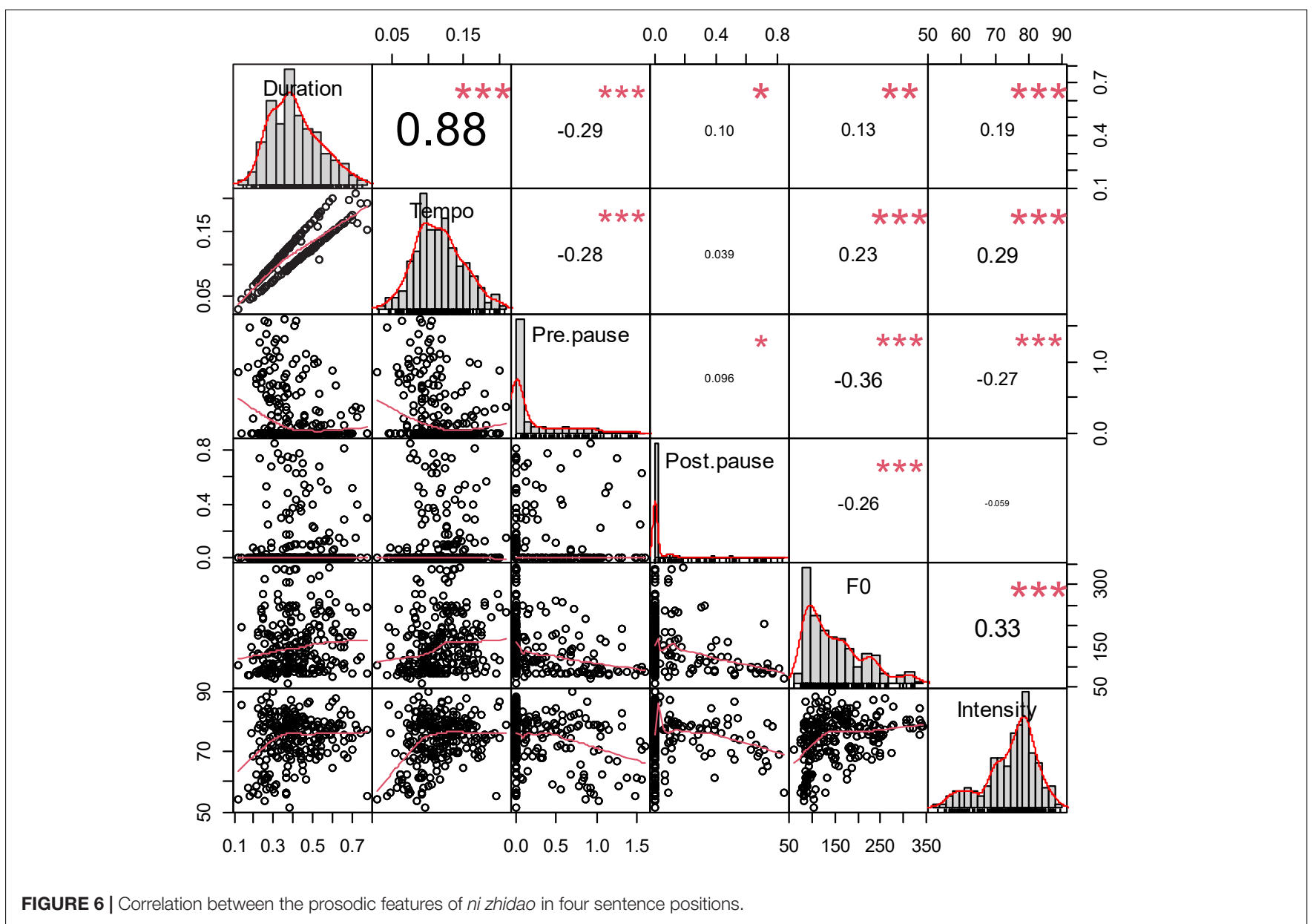


The expressive content of prosody, including the identity of the speakers, their attitude, mood, age, sex, sociolinguistic group, and other extralinguistic features (d'Alessandro, 2006), is likely to influence the pitch contour produced. Additionally, this wide range may be attributed to the diverse emotional states of the speakers, that is, the correlation of prosodic features with emotional speech (Hirschberg, 2002), typically exemplified by speakers 37, 39, 42, 65, etc., and to their distinct speaking habits caused by diversified physiological attributes. The fact that word boundaries, morphological and phonological word structures, and juncture phenomena may all contribute to determining $\mathrm{F}_{0}$ contour (Vaissière, 1983: 63) can be counted as another contributor.

Such associations deepen our understanding of prosody, and thus, to some extent, overcome the subjectivity and limitation of judging prosody merely from context. Besides, this can also provide quantitative and visual clues for investigating the pragmatics of ni zhidao.

\section{Pragmatic Functions of ni zhidao}

Based on some previous studies (including Schiffrin, 1987; Lenk, 1995, 1998; Aijmer, 1996, 2002; Brinton, 1996; Hansen, 1998; Jucker and Ziv, 1998; Erman, 2001), Shan (2014a) and Shan (2014b) explored the pragmatic functions of $n i$ zhidao on the interpersonal plane and the textual plane. On the interpersonal plane, ni zhidao constructs cognitive context, projects mental attitudes or checks the hearer's comprehension/attention, and make relevant inference ostensive from the perspectives of cognition, psychology, and social interaction. Specifically, ni zhidao implies not only the speaker's attitudes, evaluation, judgments, expectations, and demands, but the nature of the social exchange, the role played by the speaker, and the role assigned to the hearer as well. In this way, it indicates the speaker's intentions, wishes, and emotions, and in the meantime, takes into consideration the hearer's face, feelings, and social status. On the textual plane, ni zhidao helps to ensure the fluent progression of a particular stretch of discourse by creating coherence between the preceding and following sentence segments, by eliciting new topics/turns, and by emphasizing topics. Therefore, ni zhidao provides coordinates within the context by indexing sentences either to the texts (textual functions) or to the participants (interpersonal functions) (Schiffrin, 1987: 316-317).

Concerned with the communicative function of ni zhidao in simultaneous speech, this study only focuses on its interpersonal functions. Turn position serves to differentiate functional categories (Matzen, 2004). When occurring sentence-initially, -medially (within clauses and between clauses), and -finally, ni zhidao displays "subtle changes in meaning or function" (Hansen, 1997: 156). The functional load of discourse markers is embedded in dialog context; humans are better at identifying the communicative functions of discourse markers when they are judged in combination with corresponding dialog sections: "even a very limited context appears to suffice" (Gravano et al., 2007: 804). Drawing on the context in data analysis and based on Schiffrin (1987) and Matzen (2004), the current research found that ni zhidao mainly fulfills four categories of pragmatic functions, including that of initiating a topic (by grabbing/taking over the turn) when occurring sentenceinitially (see Figure 7), of holding the floor when appearing within clauses (see Figure 8), of marking coherence when making its presence between clauses (see Figure 9), and of projecting attitudes and feelings when showing up sentencefinally (see Figure 10). The distribution of the $490 \mathrm{ni}$ zhidao tokens among these four pragmatic categories is illustrated in Figure 11.

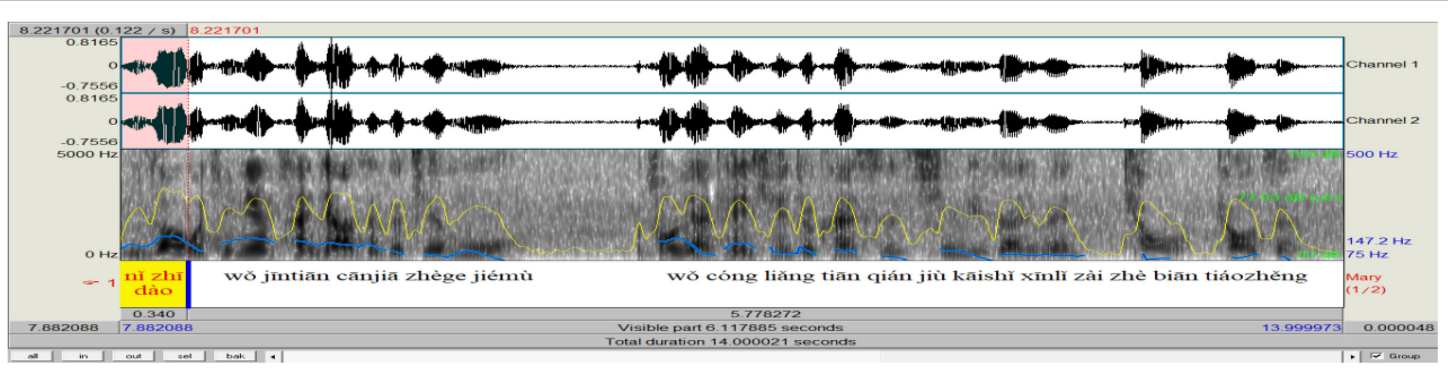

FIGURE 7 | Praat analysis of sentence-initial ni zhidao.

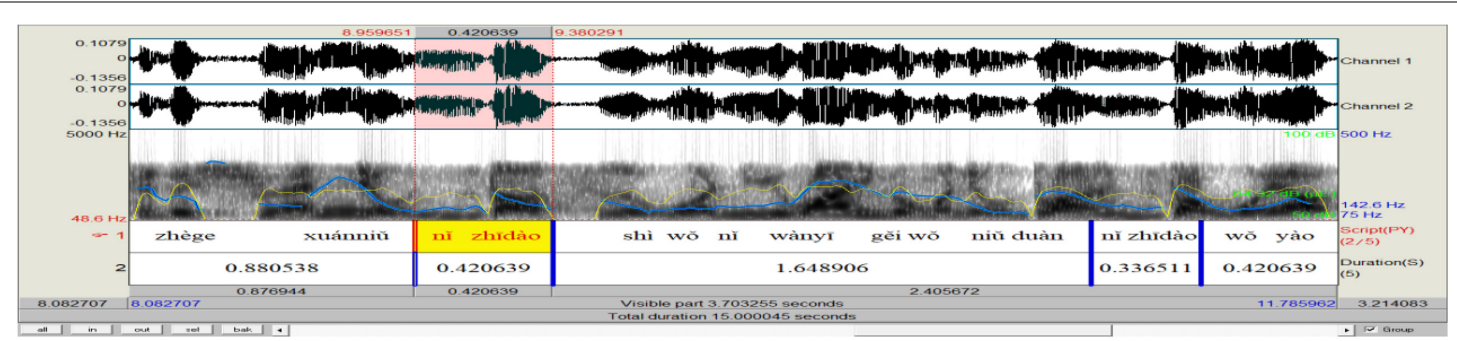

FIGURE 8 | Praat analysis of within-clause ni zhidao. 
It needs to be pointed out that each of these four broad functions can be divided into specific sub-functions. Take the floor-holding function for instance. This umbrella function will likely consist of the sub-functions of stalling time for thinking (lexical/content search), marking the false start, indicating reformulation, etc. These sub-functions will be studied in separate papers devoted to examining the sentenceinitial ni zhidao, the within-clause ni zhidao, the between-clause ni zhidao, and the sentence-final ni zhidao, respectively. In these prospective examinations, the minute prosody-pragmatics correlations of these sub-functions will be scrutinized, as claimed by Schegloff (1982); Ward and Tsukahara (2000), Gravano and Hirschberg (2009), and Buschmeier et al. (2011). The current study only makes an initial attempt to probe one broad prosody-dependent function at each of the four given sentence positions, that is, the topic-initiating function of the sentence-initial ni zhidao, the floor-holding function of the within-clause ni zhidao, the coherence-marking function of the between-clause ni zhidao, and the emotion-projecting function of the sentence-final ni zhidao. These impressionistic pragmatic categories based on immediate context and careful listening can be substantiated by acoustic data (Volín et al., 2016) in the following section.

\section{Importance of Prosodic Variables of $n i$ zhidao to Its Pragmatics and Modeling of Its Prosody-Pragmatics Correlation}

Pragmatic functions, such as holding the floor, embodying thought hesitation, managing interpersonal relationships, and expressing emotions and attitudes, rely heavily on prosody (Braga and Marques, 2004). Thus, it can tentatively be argued

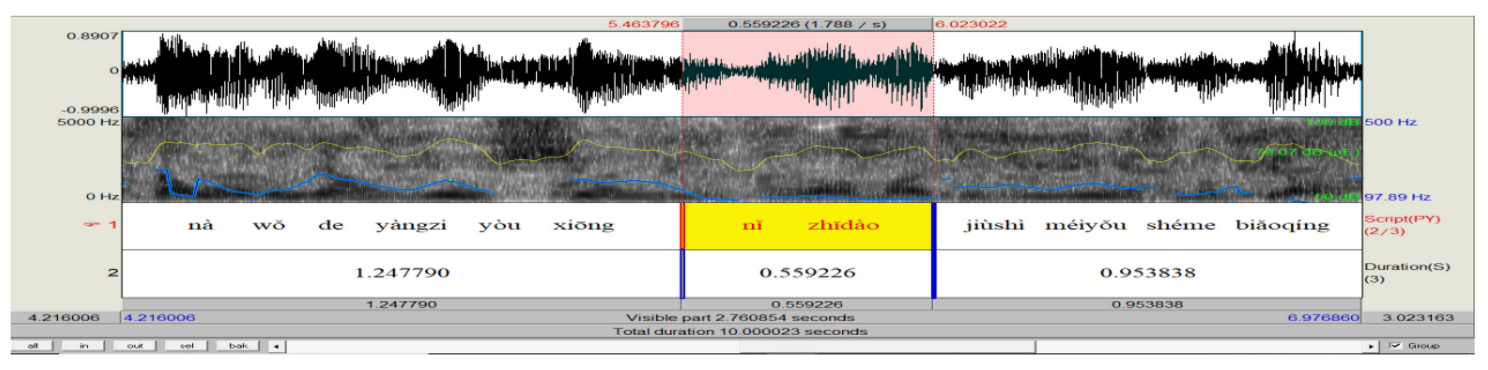

FIGURE 9 | Praat analysis of between-clause ni zhidao.

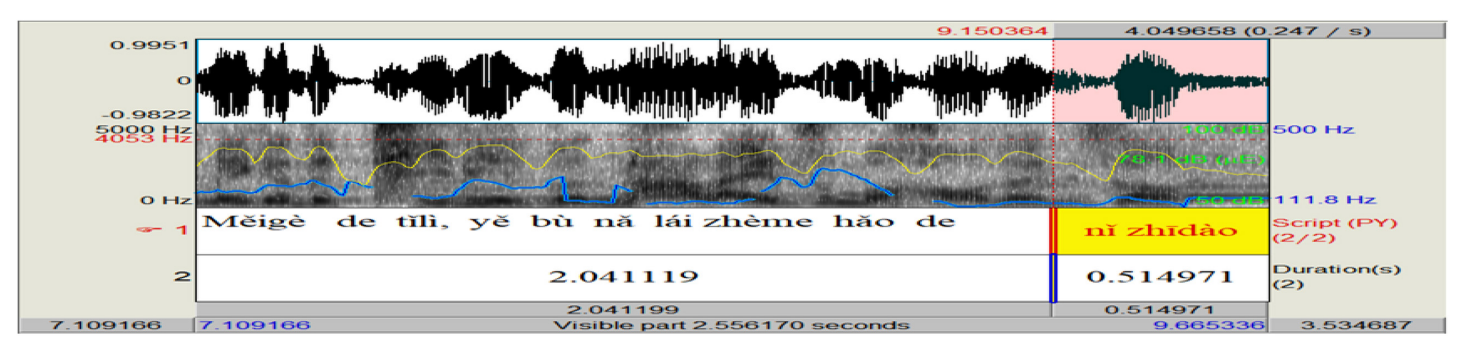

FIGURE 10 | Praat analysis of sentence-final ni zhidao.

Distribution of ni zhidao among the four identified

pragmatic categories
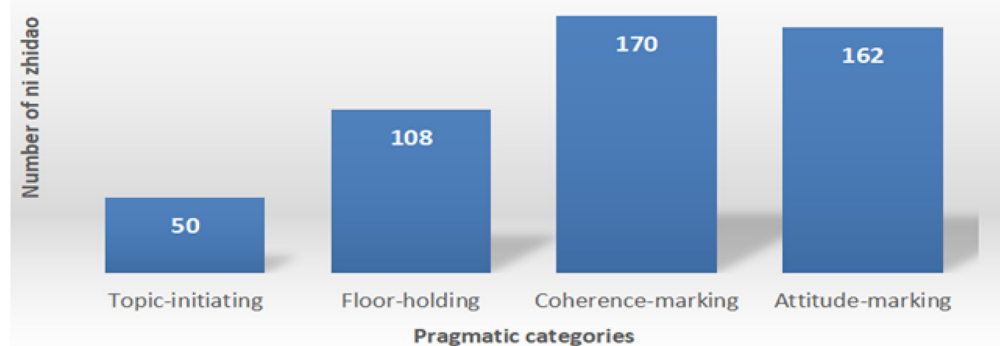

Pragmatic categories

FIGURE 11 | Distribution of ni zhidao among the four identified pragmatic categories. 
that the prosodic features of ni zhidao jointly reflect the communicative intent of the speaker and the underlying metapragmatic awareness involved. The four categories of pragmatic functions fulfilled by ni zhidao showed acoustic properties which were sufficiently specific to allow the Random Forest algorithm to distinguish them from each other statistically (Volín et al., 2016).

In this section, the Random Forest ${ }^{9}$ classification mode ${ }^{10}$ (see Endnote $\mathrm{i}$ for the script) in $\mathrm{R}$ is used to test the importance of the prosodic variables of ni zhidao, including duration, tempo, pre-pause, post-pause, $\mathrm{F}_{0}$, and intensity, to the performance of its pragmatic functions, to build a pragmatics classification model based on prosody, and to use this model to predict the pragmatic

\footnotetext{
${ }^{9}$ The GAMM, the multinomial regression, and the random forest were used as algorithms for categorization, to construct the pragmatics classification model, and the random forest was eventually adopted because it provided the best result of classification.

${ }^{10}$ \#The script for random forest:

$\mathrm{rm}($ list $=\mathrm{ls}()) \quad$ \# clear all variables

graphics.off() \# Close all figure window(s)

cat("I014") \# clear console

\# read data

Data $<$-read.csv("Ni zhidao.csv",header=T,stringsAsFactors = TRUE)

$\mathrm{n}<$-nrow(Data)

\# random forest

library("randomForest")

set.seed(9999);

$\mathrm{RF}<-$-randomForest $\left(\right.$ Pragmatics ${ }^{\sim}$,Data,importance $=$ T,localImp $=$ T,proximity $=$ T)

\# full data

RF

RF\$confusion

Imp $<-$ RF\$importance

$\operatorname{par}(\mathrm{mfrow}=\mathrm{c}(2,3))$ \# figure of the variable importance

for(i in 1:6)\{

$\operatorname{barplot}(\operatorname{Imp}[, \mathrm{i}]$, main $=\operatorname{colnames}(\operatorname{Imp})[\mathrm{i}])\}$

$\operatorname{par}(\mathrm{mfrow}=\mathrm{c}(1,1))$ \# figure of the local importance

matplot(1:(ncol(Data)-1),RF\$local,type='l',xlab =' Variables',ylab = 'Local Importance')
}

RF.pred <-predict(RF,Data)\#,type="class")

library("caret")

CM.RF <-confusionMatrix(RF.pred,Data\$Pragmatics) \# confusion matrix etc. CM.RF

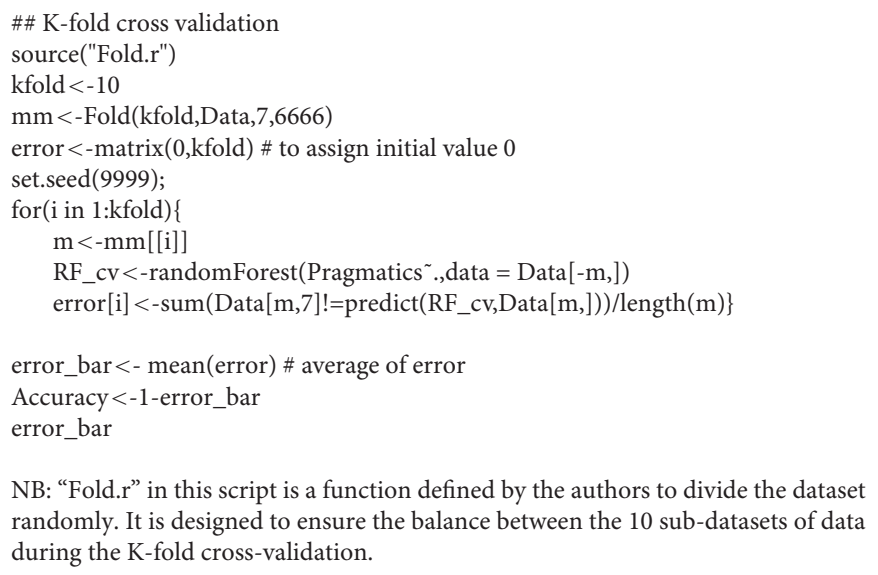

NB: "Fold.r" in this script is a function defined by the authors to divide the dataset randomly. It is designed to ensure the balance between the 10 sub-datasets of data during the $\mathrm{K}$-fold cross-validation.

functions of ni zhidao. The first five rows of the dataset ("Ni zhidao.csv"11) below provide an overview of the research data:

\begin{tabular}{lccccccc}
\hline Position & Duration Tempo & $\begin{array}{c}\text { Pre- } \\
\text { pause }\end{array}$ & Post-pause & $\mathbf{F}_{\mathbf{o}}$ & Intensity & Pragmatics \\
\hline 1 Sentence-initial & 0.294 & 0.098 & 0 & 0 & 200.437 & 78.449 & Topic-initiating \\
2 Sentence-initial & 0.261 & 0.087 & 0 & 0.036 & 106.316 & 87.978 & Topic-initiating \\
3 Sentence-initial & 0.384 & 0.128 & 0 & 0 & 305.818 & 79.646 & Topic-initiating \\
4 Sentence-initial & 0.656 & 0.164 & 0 & 0.114 & 149.297 & 73.517 & Topic-initiating \\
5 Sentence-initial & 0.412 & 0.137 & 0 & 0.108 & 337.744 & 79.253 & Topic-initiating \\
\hline
\end{tabular}

During the building of the random forest classification model, "Pragmatics" was set as the dependent variable, and "Duration," "Tempo," "Pre-pause," "Post-pause," "F $\mathrm{F}_{0}$," and "Intensity" were nominated as the independent variables. Figure 12 illustrates the established pragmatics classification model based on prosody.

From Figure 12, it is seen that the "OOB estimate of error rate" is $0 \%$. The confusion matrix indicates that the classification error of the random forest classification model is 0 . In other words, this classification model can perfectly explain all the data in the dataset because no function is attributed to the wrong class, as is displayed in the "Confusion matrix," particularly in the column of "class.error." This result, therefore, shows that the established model functions effectively at this stage of statistical analysis.

In this model, the importance of the independent variables was statistically tested and visualized through Figure $\mathbf{1 3}$. This figure shows that the six prosodic variables ("Duration," "Tempo," "Pre-pause," "Post-pause," " $\mathrm{F}_{0}$," and "Intensity") are all important ${ }^{12}$ to the performance of the four pragmatic functions of "coherence-marking," "emotion-projecting," "floor-holding," and "topic-initiating" respectively and collectively. Specifically, these variables contribute to each of these four functions differently, which is illustrated by the different heights of the individual bars. As is proved by "MeanDecreaseAccuracy" and "MeanDecreaseGini," "Post-pause," " $F_{0}$," and "Intensity" are overall more important than "Duration," "Tempo," and "Prepause."

Given that the classification model established above has been proved effective and the six prosodic variables have all been proved important in the model, this model can be applied to predict the pragmatics of ni zhidao (see Figure 14). In this figure, the "Confusion Matrix and Statistics" shows that the "Prediction" perfectly matches the "Reference," that is, none of the four categories of functions is inaccurately predicted; the "Overall Statistics" indicates that the overall accuracy rate of prediction by the pragmatics classification model based on prosody is $100 \%$; the "Statistics by class" displays that the "Balanced Accuracy" of each class of function is also $100 \%$. This means that the constructed model can perfectly predict the pragmatic functions of ni zhidao.

Next, the K-fold cross-validation (see Figure 15) is used to validate the performance of the established classification model. As can be seen, the dataset of the current study is divided into

\footnotetext{
${ }^{11}$ The dataset "Ni zhidao.csv" and the script used for this research have been uploaded to GitHub at https://github.com/victorsyhz/Raw-Data-script for reference.

${ }^{12}$ The higher the values are, the more important the variables are.
} 
ten sub-datasets, each of which is used as a testing set and the remaining nine of which are used as a training set in a recycling manner. In this way, the error of the 10 -fold cross-validation (just below 0.045 ) is finally worked out. By drawing on all the data in the dataset, this way of validation can most accurately evaluate the performance of the established model when it is used on the test set. The reasonably low error indicator of just below 0.045 shows that the constructed model performs satisfactorily, and thus there is no need to improve the model.

\section{Discussion}

The prosodic features of a sentence are primarily constrained by its communicative functions, and the latter can be realized through the former to some extent (Xiong and Lin, 2004: 116). As the results of the random forest algorithm in section "Importance of Prosodic Variables of Ni Zhidao to Its Pragmatics and Modeling of Its Prosody-Pragmatics Correlation" indicate, the six prosodic parameters of ni zhidao are significantly related to its pragmatic functions, and thus its pragmatics can objectively be revealed and understood through its prosody.

Sentence-initial $n i$ zhidao is designed to initiate a topic. To this end, the speaker mainly resorts to duration, $\mathrm{F}_{0}$ and intensity, as is statistically proved in Figure 13. The acoustic experiment showed that sentence-initial ni zhidao is characteristic of a contour of a sharp rise followed by an abrupt fall, usually with a reset. Statistics in Table 3 show that sentence-initial $n i$

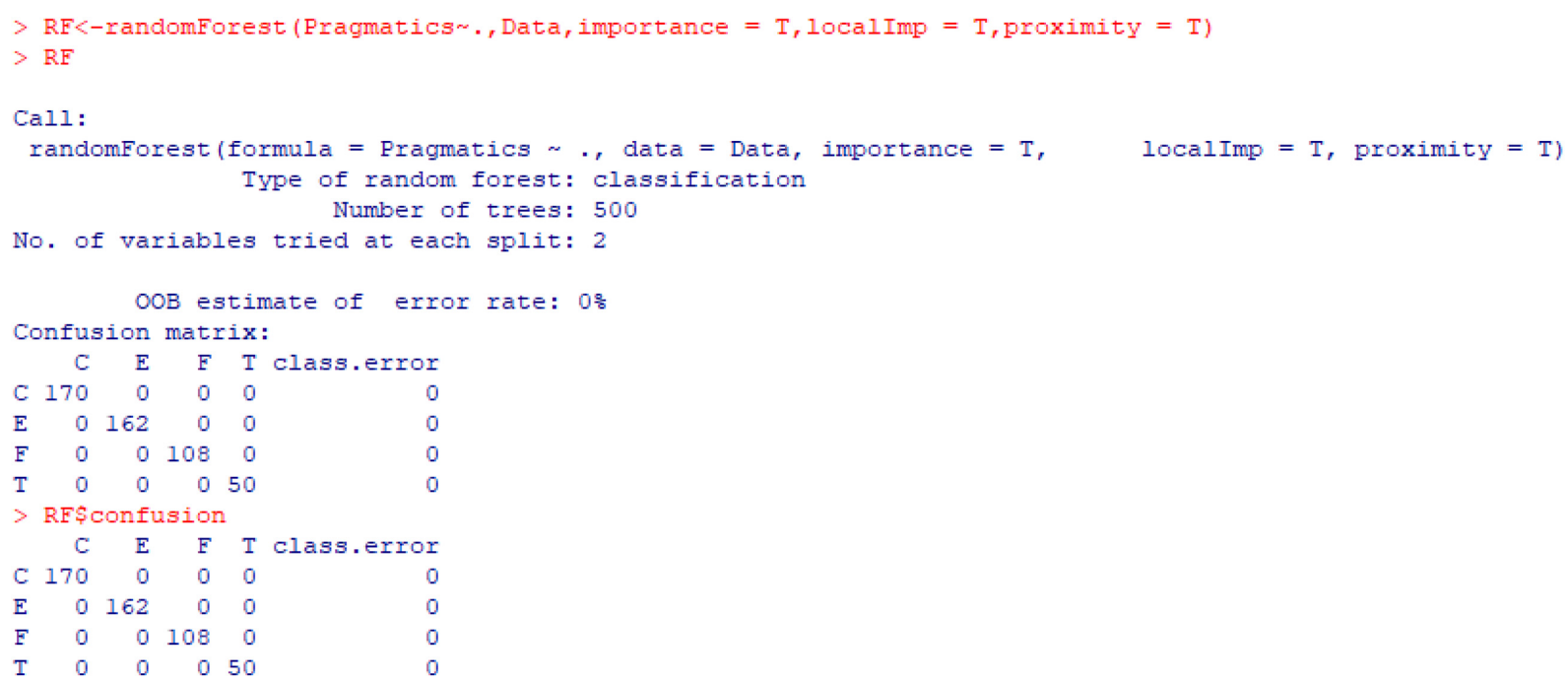

FIGURE 12 | Random forest pragmatics classification model of ni zhidao based on its prosody. In this model, "C," "E," "F," and "T" refers to the pragmatic functions of "coherence-marking," "emotion-projecting," "floor-holding," and "topic-initiating" respectively.
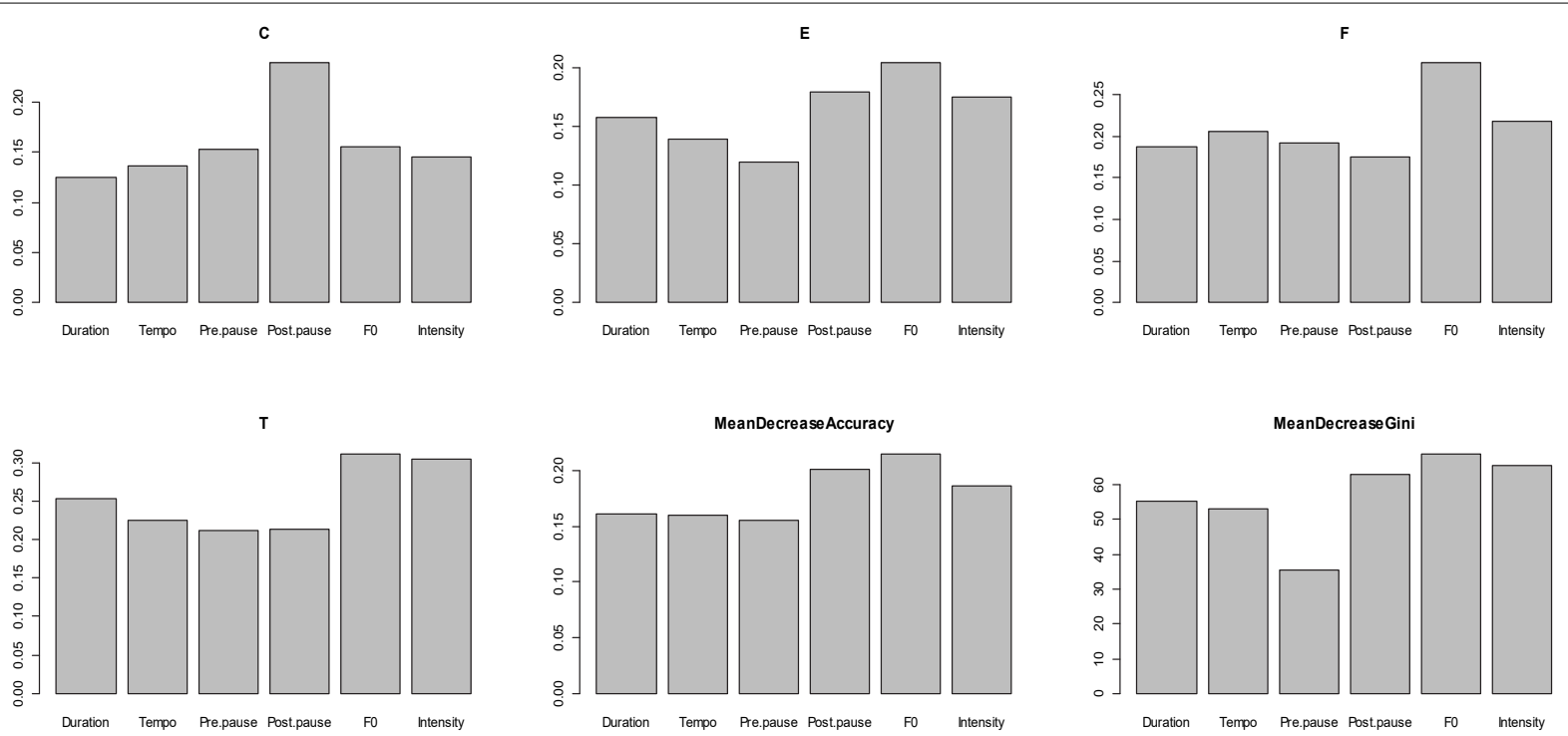

FIGURE 13 | Result of the variable importance in the classification model. 


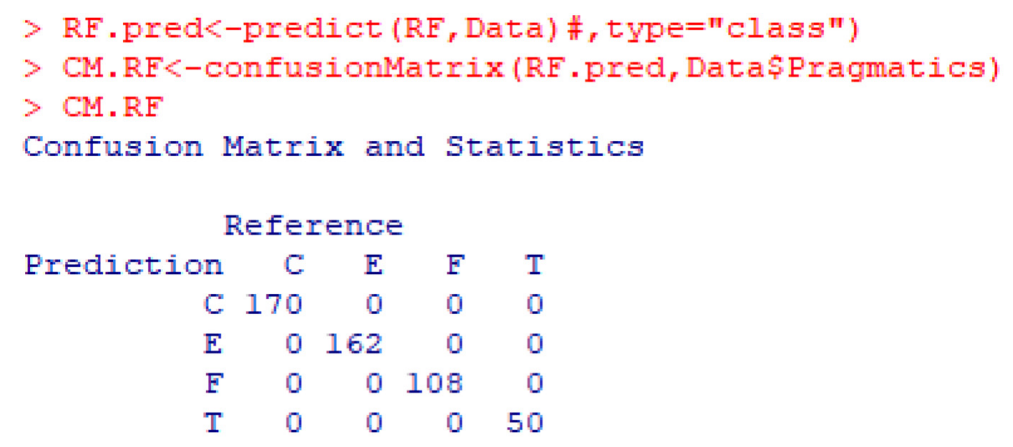

Overall Statistics

Accuracy : 1

$95 \%$ CI : $(0.9925,1)$

No Information Rate : 0.3469

P-Value [Acc > NIR]: < $2.2 \mathrm{e}-16$

Kappa : 1

Mcnemar's Test P-Value : NA

Statistics by Class:

Sensitivity
Specificity
Pos Pred Value
Neg Pred Value
Prevalence
Detection Rate
Detection Prevalence
Balanced Accuracy

$\begin{array}{rrrr}\text { Class: C Class: E Class: F Class: T } \\ 1.0000 & 1.0000 & 1.0000 & 1.000 \\ 1.0000 & 1.0000 & 1.0000 & 1.000 \\ 1.0000 & 1.0000 & 1.0000 & 1.000 \\ 1.0000 & 1.0000 & 1.0000 & 1.000 \\ 0.3469 & 0.3306 & 0.2204 & 0.102 \\ 0.3469 & 0.3306 & 0.2204 & 0.102 \\ 0.3469 & 0.3306 & 0.2204 & 0.102 \\ 1.0000 & 1.0000 & 1.0000 & 1.000\end{array}$

FIGURE 14 | Result of confusion matrix in the prediction of pragmatics.

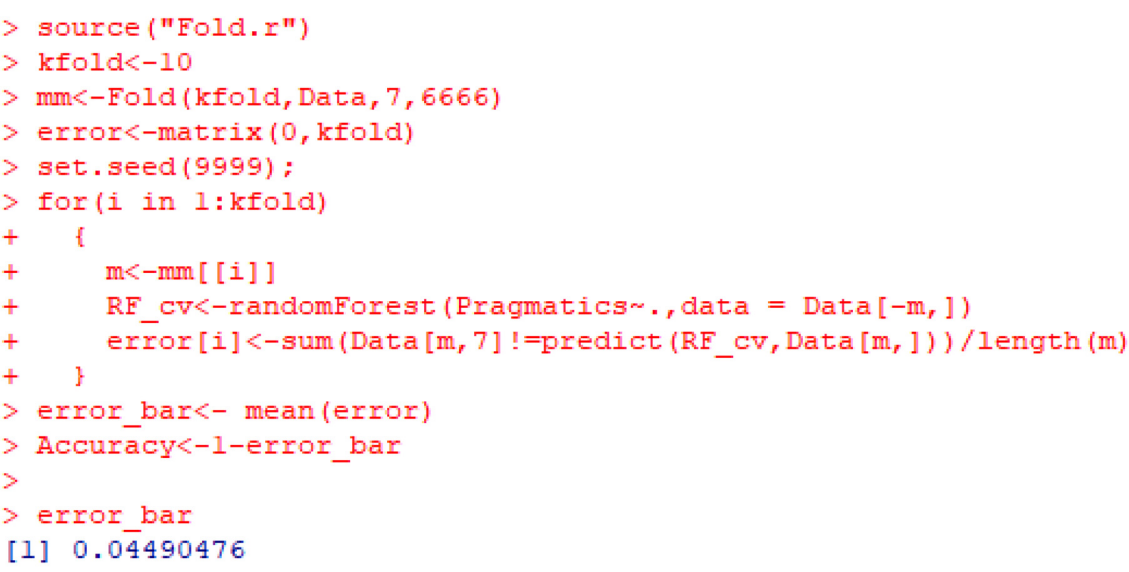

FIGURE 15 | Result of K-fold cross-validation of the performance of the established classification model. 
zhidao is uttered with the highest mean $\mathrm{F}_{0}$ among ni zhidao in the four sentence positions. It was also found that the mean $\mathrm{F}_{0}$ of sentence-initial ni zhidao is higher than that of other components in the same sentence, which is in tune with the finding in Hirschberg (2002). This high-pitched ni zhidao servers the speaker's communicative purpose of grabbing or taking over the turn (Braga and Marques, 2004). By raising the pitch, the speaker intends to draw the listener's attention to the subsequent discourse in the new topic to be initiated (Ward, 2004). We believe that the highest mean $\mathrm{F}_{0}$ value of sentence-initial ni zhidao is also related to the speaker's evaluation of the importance of the speech content: when the speakers think the speech content is important, they will raise the pitch, and otherwise, they will lower the pitch. The sentence-initial ni zhidao exhibits the most prolonged mean duration, the highest mean intensity, and the slowest tempo among the four categories of ni zhidao. This is because "intensity seems to share some of the functions of both $F_{0}$ variation and durational variation" (Vaissière, 1983: 62), $\mathrm{F}_{0}$ is positively correlated with duration (Cai et al., 1998; Xu, 1999; Zhong et al., 2001), higher pitch, more vigorous intensity, and longer duration usually focus on the same discourse component (Vaissière, 1983), and intensity increases or decreases automatically as $F_{0}$ increases or decreases ( $\mathrm{Wu}, 2002)$. This relationship between intensity and $\mathrm{F}_{0}$ has a physiological basis. They are regulated by the same mechanisms (increase in pulmonary effort and subglottal pressure, the tension of the vocal folds, etc.) (Vaissière, 1983). It was found that out of 50 tokens of sentenceinitial ni zhidao, 32 (64\%) are not followed by pauses, and $18(36 \%)$ are followed by pauses. In natural speech, pauses can appear anywhere in the sentence (Goldiscourse markeranEisler, 1968) due to three needs: grammar, expression of meaning, and breathing (Guo, 1993). As a prosodic word, ni zhidao's syllables sound closely connected, "prosodically separate" (Wichmann et al., 2010: 40) from the following utterance components, as they are of an $\mathrm{F}_{0}$ variation group and carry only one word stress (Wang, 2011). Therefore, the pauses following it do not result from grammatical needs. Sentence-initially, there is no physiological need for pauses for breathing. The pauses following it are thus out of the need for expression. Whether such a pause occurs or not depends on whether the speaker needs to win time to think or not. The pauses of different duration reflect the different thinking time spent by the speaker in organizing the subsequent speech. If the speaker does not encounter expression obstacles, such as hesitation, thinking, etc., he can fluently say what he wants to express, and there will be no pause in the speech flow. These prominent prosodic features of sentence-initial $n i$ zhidao not only attract the listener's attention to the followup sentence but also hint to the listener the importance of the subsequent sentence, encoding and conveying the speaker's communicative intent and thus meta-pragmatic awareness that "I want to call your attention to the topic to be initiated in the following sentence."

When used as a floor-holding means, within-clause ni zhidao is a relatively independent prosodic word acoustically, and it is easily separated from the preceding and following sentence components. Figure 13 reveals that $\mathrm{F}_{0}$ and intensity are the most important indicators of the floor-holding $n i$ zhidao. In this usage, ni zhidao features a continuous flat $\mathrm{F}_{0}$ contour, usually with a reset after it, but occasionally displays a flat contour with a reset within it. It is produced with the second highest mean $\mathrm{F}_{0}$ and intensity among $n i$ zhidao in the four sentence positions. Within the embedding clause, it sometimes carries a lower mean $\mathrm{F}_{0}$ and a lower intensity, a lower mean $\mathrm{F}_{0}$ but a similar intensity, or a mean $\mathrm{F}_{0}$ higher than the preceding components and lower than the succeeding components but a higher mean intensity. This prosodic performance of within-clause ni zhidao can be deemed as a signal of mental hesitation, most possibly indicative of the speaker's struggle in the production of intended speech. In comparison with other components in the same turn, the mean tempo of within-clause ni zhidao is sometimes faster and sometimes slower, and it is faster than that of sentenceinitial ni zhidao but slower than that of between-clause and sentence-final ni zhidao. The tempo of within-clause ni zhidao depends on the length of thinking time used by the speaker: the longer the thinking time is, the longer its duration is and the slower its tempo is. In natural speech, people often do not first think about the content to be expressed and then utter it fluently. Instead, they think and speak while correcting, explaining, or supplementing what has been said. Therefore, the speaker often pauses in the middle of the sentence or between the syntactic components (Grosjean et al., 1979). To avoid too long a pause and thus an embarrassing temporary communication break-off, and even a loss of turn, speakers often use fillers to indicate their mental or thinking state while maintaining the current turn. Being "behavior-driven" (Xue and Liu, 2008), within-clause ni zhidao suggests that the speaker has something to say, fulfilling a floor-holding function. If the time won through uttering ni zhidao and through the possible pause preceding it is not long enough for the speaker to pinpoint what is to be produced, there is likely to be a pause following it. Of the 108 tokens of within-clause ni zhidao, $12(11.1 \%)$ are preceded by a pause, $10(9.3 \%)$ are followed by a pause, $20(18.5 \%)$ are both preceded and followed by a pause, and 66 (61.1\%) are neither preceded nor followed by a pause. This result shows that because "where there is a pause, there is a danger of losing the turn" (Ward, 2004), the speaker endeavors not to pause within the clause for fear of losing the floor or causing embarrassment. These prosodic performances of within-clause ni zhidao are closely related to one another (as is shown in Figure 6), and they jointly decipher the speaker's intended pragmatic meaning that "I want to hold the floor here, so please allow me time to search for the appropriate content or linguistic items."

As with the between-clause ni zhidao, post-pause is the most important indicator of its coherence-marking function. Of the 170 tokens of between-clause ni zhidao, 92 (54.1\%) are followed by a pause. This post-pause is most likely to result from the purpose of expression, in that there is no need of pause for breathing after such a short prosodic word, and there is no need of pause for marking the boundary of 
the prosodically independent ni zhidao. This ni zhidao serves as a link, which indexes both the preceding and succeeding clauses and thus binds them into a coherent proposition. The speaker employs it, coupled with the pause following it, provides the listener with sufficient time to work out the logic between the clause preceding it and the clause to be uttered. According to statistics, 106 (63.4\%) tokens of betweenclause ni zhidao are preceded by a pre-pause, which may be caused by a grammatical need of marking the clause boundary, by a breathing need following a clause, or by an expressive need for time to prepare the succeeding clause and prepare the listener for it. Thus, this pre-pause is most elusive. The between-clause ni zhidao is characteristic of a continuous flat contour. Its mean $\mathrm{F}_{0}$ and intensity are relatively lower than sentence-initial and within-clause ni zhidao but comparatively higher than sentence-final ni zhidao. Its mean tempo is faster than that of sentence-initial and within-clause ni zhidao but slower than that of sentence-final ni zhidao. Compared with other components in the same sentence, it is sometimes faster and sometimes slower, which is decided by the length of time used by the speaker to prepare the listener for the following clause. In a word, the characteristic prosody of between-clause ni zhidao is intended to communicate the speaker's pragmatic purpose that "I want to make ostensive the coherent semantic relations between the preceding and succeeding clauses."

The prosody of within-clause and between-clause ni zhidao does not show any apparent regularity, and the reasons behind this deserve exclusive studies in the future. However, this research found that like the prosody of sentence-initial $n i$ zhidao, the prosody of sentence-final ni zhidao also exhibits apparent regularity. As is indicated in Figure 13, $\mathrm{F}_{0}$ and intensity are once again the most essential variables facilitating sentence-final $n i$ zhidao performing the emotion-projecting function. According to statistics, it has the lowest mean $\mathrm{F}_{0}$ and intensity and the fastest mean tempo among the four categories of ni zhidao. Compared with other components in the same sentence, its mean $\mathrm{F}_{0}$ and intensity are lower, its mean tempo is faster, and its mean duration is shorter. Its $\mathrm{F}_{0}$ contour is generally flat, with a moderate rise and, or fall within it. These prosodic attributes have a lot to do with the sentence-final position. The phrase at the end of the topic has a narrower tonal range, a lower pitch, and a faster tempo (Hirschberg, 2002). In general, the sentence-final prosodic word carries the lowest $\mathrm{F}_{0}$ in a complete sentence (Wang, 2011). This is the FINAL LOWERING, compression of the pitch range during the last half-second or so of an utterance (Caspers, 1998). The compression of pitch range within about half a second before the end of the speech can indicate that the speaker has finished the current turn (Hirschberg, 2002). $73(45.1 \%)$ of the 162 sentence-final tokens are preceded by a pause, which may be triggered by the speaker's breathing need and, or grammatical need. These prosodic hallmarks of sentence-final ni zhidao convey the speaker's meta-pragmatic awareness that "I want you to identify with me in terms of the strong attitude and feeling that I have projected into the preceding sentence."
Prosody is a prominent phonetic feature of natural speech, which is extremely important but often overlooked in the research of spontaneous speech. This characteristic of speech reflects the actual usage of language in the improvised context. It intuitively displays the rhythm of the speaker's speech, as well as the speaker's attitude toward and emotion at people and things. It thus provides objective evidence for judging the pragmatic functions of discourse. Praat speech software and algorithms in $\mathrm{R}$ can represent the prosodic features of ni zhidao and the potential interaction between its prosodic features and pragmatic functions statistically, graphically, and thus visually, therefore achieving relatively simple, effective, and reliable semiautomated processing of spontaneous speech. Accordingly, the "invisible" meta-pragmatic awareness underlying discourse is made "visible" to a large extent. Statistical analysis and modeling can put the study of discourse markers on a more objective and scientific footing.

\section{CONCLUSION}

The intrinsic mechanism of spoken discourse is maintained by three integral components, phonological (the phonetic and prosodic feature), morphological (the morphological and syntactic configuration), and propositional (the semantic and pragmatic meaning). However, academic circles have mostly been inferring and summarizing the pragmatic functions of discourse markers subjectively in specific contexts, based on a few examples or a small-sized corpus. Although some researchers (e.g., Hirschberg, 2002; Matzen, 2004; Braga and Marques, 2004; Wichmann et al., 2010; Beňuš, 2012; Abuczki, 2014; Cabarrão et al., 2015; Gonen et al., 2015; Volín et al., 2016) have investigated how discourse markers' prosody relates to their pragmatics, they have neither investigated their prosodypragmatics interaction statistically nor built a model to predict their pragmatic functions automatically.

Based on a relatively large-scaled corpus of media interviews, this study examined the prosody-pragmatics interaction of $n i$ zhidao. It was found that ni zhidao exhibited different prosodic features when occurring in four sentence positions, that it fulfilled four broad pragmatic functions of initiating a topic, holding the floor, marking coherence, and projecting emotions, and that the prosody-pragmatics correlation of ni zhidao can statistically be investigated and modeled, and the constructed classification model can be used to predict the pragmatics of $n i$ zhidao highly accurately. These findings seem to confirm that the prosody of ni zhidao plays a role in deciphering its different pragmatic functions.

Speech analyses and computational statistics based on the natural spoken language are well established in computational linguistics and speech engineering. Although not used in the studies of discourse markers, these methods are fully applicable to discourse marker research, proved in this study. Within the framework of this paper, we can not only explain abstract pragmatic phenomena in discourse analysis but also clearly and objectively grasp the intrinsic mechanisms of prosodypragmatics interaction. A combination of formal and functional 
approaches and corpus data and intellectual inquiry is not only feasible and effective but also inevitable and potent in the future research of language in general and discourse markers in particular.

\section{DATA AVAILABILITY STATEMENT}

The original contributions presented in the study are included in the article/Supplementary Material, and further inquiries can be directed to the corresponding author/s.

\section{REFERENCES}

Abt, V., and Seesholtz, M. (1994). The shameless world of phil, sally and oprah: television talk shows and the deconstructing of society. J. Pop. Cult. 28, 195-215. doi: 10.1111/j.0022-3840.1994.2801_171.x

Abuczki, A. (2014). On the disambiguation of multifunctional discourse markers in multimodal interaction. J. Multimodal User In. 8, 121-134. doi: 10.1007/ s12193-013-0136-x

Aijmer, K. (1996). Conversational Routines in English: Convention and Creativity. London: Longman.

Aijmer, K. (2002). English Discourse Particles: Evidence From A Corpus. Amsterdam: John Benjamins. doi: 10.1075/scl.10

Akar, D., and Öztürk, B. (2020). "Chapter 10: The discourse marker hani in Turkish," in Information-Structural Perspectives On Discourse Particles, eds P.-Y. Modicom and O. Duplâtre (Amsterdam: John Benjamins Publishing Company), 252-276. doi: 10.1075/slcs.213.10aka

Beňuš, $\check{S}$ (2012). "Prosodic forms and pragmatic meanings: the case of the discourse marker 'no' in slovak,". Proceedings of CogInfoCom 2012, Kosice, Slovakia. doi: 10.1109/CogInfoCom.2012.6421961

Blakemore, D. (1987). Semantic Constraints On Relevance. Oxford: Blackwell.

Blakemore, D. (2002). Relevance and Linguistic Meaning. Cambridge: Cambridge University Press. doi: 10.1017/CBO9780511486456

Blakemore, D. (2011). On the descriptive ineffability of expressive meaning. J. Pragmat. 11, 3537-3550. doi: 10.1016/j.pragma.2011.08.003

Bolinger, D. (1989). Intonation and Its Uses: Melody and Grammar in Discourse. Stanford, CA: Stanford University Press.

Braga, D., and Marques, M. A. (2004). "The pragmatics of prosodic features in the political debate," in Proceedings of Speech Prosody 2004 (Japan: Nara), 321-324.

Brinton, L. J. (1996). Pragmatic Markers In English: Grammaticalization And Discourse Functions. New York, NY: Mouton de Gruyter. doi: 10.1515/ 9783110907582

Brown, L., and Prieto, P. (2017). ““(Im)politeness: prosody and gesture”, in The Palgrave Handbook of Linguistic (Im)politeness, eds J. Culpeper, M. Haugh, and D. Z. Kádár (London: Palgrave Macmillan), 357-379. doi: 10.1057/978-1-13737508-7_14

Brown, L., Winter, B., Idemaru, K., and Grawunder, S. (2014). Phonetics and politeness: perceiving Korean honorific and non-honorific speech through phonetic cues. J. Pragmat. 66, 45-60. doi: 10.1016/j.pragma.2014.02.011

Buschmeier, H., Malisz, Z., Wlodarczak, M., Kopp, S., and Wagner, P. (2011). “Are you sure you're paying attention?'-'Uh-huh'. Communicating understanding as a marker of attentiveness," in Proceedings of Interspeech 2011, (Florence: ISCA). doi: 10.21437/Interspeech.2011-540

Cabarrão, V., Moniz, H., Ferreira, J., Batista, F., Trancoso, I., and Mata, A. I. et al. (2015). "Prosodic classification of discourse markers," in Proceedings of ICPhS 2015, Glasgow, Scotland.

Cai, L., Zhang, W., and Hu, Q. (1998). Prosody learning and simulation for Chinese text to speech system. J. Tsinghua Univ. 1, 95-98.

Cao, J. (2003). "The features and changes of speech tempo," in Paper Presented at The $6^{\text {th }}$ National Modern Phonetics Symposium, Tianjin Normal University, $17-20$.

Caspers, J. (1998). Who's next? the melodic marking of question versus continuation in dutch. Prosody and Conversation (special issue). Lang. Speech. 41, 3-4. doi: 10.1177/002383099804100407

\section{AUTHOR CONTRIBUTIONS}

The author confirms being the sole contributor of this work and has approved it for publication.

\section{SUPPLEMENTARY MATERIAL}

The Supplementary Material for this article can be found online at: https://www.frontiersin.org/articles/10.3389/fpsyg. 2021.716791/full\#supplementary-material

Chen, G., and Liang, M. (2017). Automatic detection of verb form errors in Chinese EFL learners' written English: a study based on link grammar. J. Chin. Inform. Process. 6, 196-204.

Chen, X. (2002). Interpreting the implicature of epanadiplosis by way of discourse markers. J. PLA Univ. For. Lang. 3, 12-15.

d'Alessandro, C. (2006). "Voice source parameters and prosodic analysis," in Methods in Empirical Prosody Research, ed. S. Sudhoff (Berlin: Walter de Gruyter).

Dehé, N., and Wichmann, A. (2010a). Sentence-initial I think (that) and I believe (that): prosodic evidence for use as main clause, comment clause and discourse marker. Stud. Lang. 1, 36-74. doi: 10.1075/sl.34.1.02deh

Dehé, N., and Wichmann, A. (2010b). The multifunctionality of epistemic parentheticals in discourse: prosodic cues to the semantic pragmatic boundary. Funct. Lang. 1, 1-28. doi: 10.1075/fol.17.1.01deh

Der, C., and Marko, A. (2010). A pilot study of Hungarian discourse markers. Lang. Speech 53, 135-180. doi: 10.1177/0023830909357162

Didirková, I., Christodoulides, G., and Simon, C. A. (2018). "The prosody of discourse markers alors and et in French: s speech production study," in Proceedings of Speech Prosody, Vol. 9, Poznan, Poland. doi: 10.21437/ SpeechProsody.2018-102

Dong, X. (2010). A discourse marker derived from clausal from: wo gao su ni ('I tell you'). Linguist. Sci. 3, 279-286.

Erman, B. (2001). Pragmatic markers revisited with a focus on you know in adult and adolescent talk. J. Pragmat. 33, 1337-1359. doi: 10.1016/S0378-2166(00) 00066-7

Fang, M. (2005). On grammatical bleaching of the evidential and epistemic verbs: from complement-taking predicates to pragmatic marker. Chin. Lang. 6, 16-23.

Fang, Y. (2016). Text worlds and characterization: exemplified by Arthur Miller's two memory plays. Foreign Lang. Lit. 6, 26-31.

Fedriani, C., and Sanso, A. (2017). Pragmatic Markers, Discourse Markers And Modal Particles. Amsterdam: John Benjamins Publishing Company. doi: 10. $1075 /$ slcs. 186

Fraser, B. (1987). "Pragmatic formatives," in Paper Presented at The Pragmatic Perspective: Selected Papers From The 1985 International Pragmatics Conference, eds J. Verschueren and M. Bertuccelli-Papi (Amsterdam: Benjamins), 179-193. doi: $10.1075 /$ pbcs.5.14fra

Fraser, B. (1990). An approach to discourse markers. J. Pragmat. 3, 383-395. doi: 10.1016/0378-2166(90)90096-V

Fraser, B. (1999). What are discourses? J. Pragmat. 7, 931-952. doi: 10.1016/S03782166(98)00101-5

Fraser, B. (2009). Topic orientation markers. J. Pragmat. 41, 48-53. doi: 10.1016/j. pragma.2008.08.006

Fraser, B. (2015). The combining of discourse markers-a beginning. J. Pragmat. 86, 48-53. doi: 10.1016/j.pragma.2015.06.007

Fujisaki, H., and Sudo, H. (1971). A generative model for the prosody of connected speech in Japanese. Annu. Rep. English Res. Ins. Univ.Tokyo 30, 75-80.

Gao, G., and Wei, N. (2017). Meaning-shift unit: implications and the analytic procedure. Foreign Lang. Teach. 6, 12-21.

Goldiscourse markeran-Eisler, F. (1968). Psycholinguistics: Experiments in Spontaneous Speech. London: Academic Press.

Gonen, E., Livnat, Z., and Amir, N. (2015). The discourse marker axshav ('now') in spontaneous spoken Hebrew: Discursive and prosodic features. J. Pragmat. 89, 69-84. doi: 10.1016/j.pragma.2015.09.005 
Gravano, A., and Hirschberg, J. (2009). "Turn-yielding cues in task-oriented dialogue," in Proceedings of SIGDIAL 2009, (London: ISCA), 253-261. doi: 10.3115/1708376.1708412

Gravano, A., Beňuš, Š, Chávez, H., Hirschberg, J., and Wilcox, L. (2007). "On the role of context and prosody in the interpretation of okay," in Proceedings of the 45th Annual Meeting of the Association of Computational Linguistics, Prague, Czech Republic, 800-807.

Gray, F. R. (2010). It's Like 120 Milliseconds: A Search for Grammaticalization in the duration of Like in Five Functions. MA Thesis, University of Georgia.

Gries, S. (2017). Quantitative corpus linguistics with R: a practical introduction, 2nd Edn. London: Routledge.

Grosjean, F., Grosjean, L., and Lane, H. (1979). The patterns of silence: performance structures in sentence production. Cogn. Psychol. 11, 58-81. doi: 10.1016/0010-0285(79)90004-5

Guo, J. (1993). Comprehensive Phonetics. Fujian: Fujian People’s Press.

Halliday, M. A. K., and Matthiessen, Christian M. I. M. (2004). An Introduction To Functional Grammar, 3rd Edn. London: Hodder Arnold.

Hansen, M.-B. M. (1997). The Functions Of Discourse Particles: A Study With Special Reference To Spoken Standard French. Philadelphia: John Benjamins Publishing Company.

Hansen, M.-B. M. (1998). The Function of Discourse Particles. Pragmatics \& Beyond New Series. Amsterdam: John Benjamins. doi: 10.1075/pbns.53

He, A. (2010). A survey of corpus's "pedagogic processing. Foreign Lang. China 4, 47-52.

He, Z., and Mo, A. (2002). Discourse markers and bridging reference. J. Guangdong Univ. Foreign Stud. 1, 1-6.

Heritage, J. (1997). "Conversation analysis and institutional talk," in Qualitative Research: Theory, Method And Practice, ed. D. Silverman (Michigan: Sage), 103-147.

Hirschberg, J. (2002). Communication and prosody: functional aspects of prosody. Speech Commun. 36, 31-43. doi: 10.1016/S0167-6393(01)00024-3

Hirschberg, J., and Litman, D. (1987). "Now let's talk about now: identifying cue phrases intonationally," in Proceedings of the 25th Annual Meeting of the Association for Computational Linguistics, Stanford, CA, 163-171. doi: 10.3115/ 981175.981198

Hirschberg, J., and Litman, D. (1993). Empirical studies on the disambiguation of cue phrases. Comput. Linguist. 19, 501-530.

Hirschberg, J., and Swerts, M. (1998). Special double issue on prosody and conversation. Lang. Speech 41, 3-4. doi: 10.1177/002383099804100401

Hu, K., and Xie, L. (2017). Towards a corpus-base study of translator's style. Chin. Transl. J. 2, 12-18.

Hyland, K., and Tse, P. (2012). 'She has received many honors': identity construction in article bio Statements. J. English Acad. Purp. 2, 155-165. doi: 10.1016/j.jeap.2012.01.001

Jucker, A. H., and Ziv, Y. (1998). Discourse Markers: Descriptions And Theory. Philadelphia: John Benjamins. doi: 10.1075/pbns.57

Keller, E., and Zellner, B. (1996). “A Timing model for Fast French," in Paper Presented at York Papers in Linguistics 17, University of York, 53-75.

Lai, C. (2009). "Perceiving surprise on cue words: prosody and semantics interact on right and really," in Proceedings of the 10th Interspeech Conference. Brighton, UK, 1-4. doi: 10.21437/Interspeech.2009-475

Lenk, U. (1995). "Discourse markers and conversational coherence," in Organization in Discourse. Proceedings from the Turku Conference, eds B. Wårvik, S.-K. Tanskanen, and R. Hiltunen (Turku: University of Turku), 341-352.

Lenk, U. (1998). Marking Discourse Coherence: Functions of Discourse Markers In Spoken English. Tübingen: Gunter Narr Verlag.

Li, A. (2002). Prosodic analysis on conversation in standard Chinese. Chin. Lang. 6, 525-535.

Li, A., et al. (2006). "Comparative analysis of prosodic features of English sentences at different speeds," in Paper presented at The 7th China Conference on Phonetics and International Forum on Frontiers of Phonetics, Peking University.

Li, X., Xiang, M., and Cao, D. (2018). Semantic Trace and pragmatic functions of discourse markers: the case of “you know". Foreign Lang. Teach. 2, 90-98.

$\mathrm{Li}, \mathrm{Z}$. (2014). On the source of discourse marker bieshuo: with comments on the sources of discourse markers. Chin. Teach. World. 2, 222-229.

Liao, Q. (2000). Corpus and translation studies. Foreign Lang. Teach. Res. 5, $380-384$.
Liberman, M., and Sag, I. A. (1974). "Prosodic form and discourse function," in In Papers of the 10th Regional Meeting, Chicago Linguistic Society, 416-427.

Lin, M. (2002). Prosodic structure and lines of $F_{0}$ top and bottom of sentences in Chinese. Contemp. Linguist. 4, 254-265.

Liu, L. (2006). The discourse marker ni zhidao ('you know'). Chin. Lang. 5, 423-432.

Liu, Z., and Wang, M. (2017). A comparison of the style of the source text and the six Chinese versions of The Old Man and the Sea on quantitative and qualitative terms. Foreign Lang. Educ. 5, 73-79.

Local, J., and Walker, G. (2004). Abrupt-joins as a resource for the production of multi-unit, multi-action turns. J. Pragmat. 8, 1375-1403. doi: 10.1016/j.pragma. 2004.04.006

Ma, Q. (2017). The prosodic representation and types of stress on Chinese tonal focus. Stud. Prosodic Grammar 1, 32-72.

Maschler, Y. (2009). Metalanguage In Interaction: Hebrew Discourse Markers. Amsterdam: John Benjamins Publishing Company. doi: 10.1075/pbns.181

Matzen, L. (2004). "Discourse markers and prosody: a case study of so," in Language, Thought And Reality, eds G. D. Fulton, W. J. Sullivan, and A. R. Lommel (Ottawa, ON: The Linguistic Association Of Canada And The United States), 75-94.

Nadeu, M., and Prieto, P. (2011). Pitch range, gestural information, and perceived politeness in Catalan. J. Pragmat. 43, 841-854. doi: 10.1016/j.pragma.2010.09. 015

Nebot, A. C. (2021). Prosodic modulation as a mark to express pragmatic values: the case of mitigation in Spanish. J. Pragmat. 181, 196-208. doi: 10.1016/j. pragma.2021.05.028

Petukhova, V., and Bunt, H. (2009). “Towards a multidimensional semantics of discourse markers in spoken dialogue," in Proceedings of the $8^{\text {th }}$ International Conference on Computational Semantics, Tilburg, 157-168. doi: 10.3115/ 1693756.1693773

Popescu-Belis, A., and Zufferey, S. (2011). Automatic identification of discourse markers in dialogues: an in-depth study of like and well. Comput. Speech Lang. 25, 499-518. doi: 10.1016/j.csl.2010.12.001

Ran, Y. (2002). On the pragmatic functions of discourse marker "you know". J. PLA Univ. Foreign Lang. 4, 10-15.

Redeker, G. (1991). Review article: linguistic markers of discourse structure. 29, 1139-1172.

Rendle-Short, J. (2003). "So what does this show us?": analysis of the discourse marker 'so' in seminar talk. Aust. Rev. Appl. Linguist. 26, 46-62. doi: 10.1075/ aral.26.2.04ren

Rhee, S. (2020). Pseudo-hortative and the development of the discourse marker eti poca ('well, let's see') in Korean. J. Hist. Pragmat. 21, 53-82. doi: 10.1075/jhp. 00036.rhe

Romero-Trillo, J. (2015). 'It is a truth universally acknowledged', you know? The role of adaptive management and prosody to start a turn in conversation. Pragmat. Soc. 6, 117-145. doi: 10.1075/ps.6.1.06rom

Schegloff, E. A. (1982). "Discourse as an interactional achievement: some uses of 'uh huh' and other things that come between sentences," in Analyzing Discourse: Text and Talk, ed. D. Tannen (Georgetown: Georgetown University Press), 71-93.

Schiffrin, D. (1987). Discourse Markers. Cambridge: Cambridge University Press. doi: 10.1017/CBO9780511611841

Schiffrin, D. (1994). Approaches to Discourse. Oxford: Blackwell.

Schiffrin, D. (2001). "Discourse Markers," in The Handbook of Discourse Analysis, eds D. Schiffrin, D. Tannen, and H. E. Hamilton (Oxford: Blackwell).

Schiffrin, D. (2003). We knew that's it: retelling the turning point of a narrative. Discourse Stud. 4, 535-561. doi: 10.1177/14614456030054005

Schourup, L. (1999). Discourse markers. Lingua 4, 227-265. doi: 10.1016/S00243841(96)90026-1

Searle, J. R. (1969). Speech Acts: An Essay In The Philosophy Of Language. Cambridge: Cambridge University Press. doi: 10.1017/CBO9781139173438

Shan, Y. (2014a). Pragmatic functions of ni zhidao as a discourse marker: a study from the perspectives of cognition, psychology and social interaction. Tongji Univ. J. 1, 119-124.

Shan, Y. (2014b). A pragmatic analysis of ni zhidao as as discourse marker in Chinese spontaneous speech. J. Zhejiang Int. Stud. Univ. 2, 63-70.

Shan, Y. (2015). The prosodic features of the discourse marker ni zhidao in Chinese spontaneous speech. Lang. Teach. Linguist. Stud. 3, 70-78. 
Sohn, S.-O. S., and Kim, S. H. (2014). "The interplay of discourse and prosody at the left and right periphery in Korean: an analysis of kuntey ('but')," in Discourse functions at the left and right periphery: cross-linguistic investigations of language use and language change, eds K. Beeching and U. Detges (Leidon: Brill), 221-250. doi: 10.1163/9789004274822_010

Tabor, W., and Traugott, E. C. (1998). "Structural scope expansion and grammaticalization," in The Limits of Grammaticalization, eds G. A. Ramat and P. J. Hopper (Philadelphia: John Benjamins), 229-272. doi: 10.1075/tsl.37.11tab

Tanno, K. (2018). The role of discourse strategies in the grammaticalization of the Japanese discourse marker dakara. Lang. Linguist. 4, 592-634. doi: 10.1075/lali. 00022.tan

Tao, H. (2003). Phonological, grammatical, and discourse evidence for the emergence of zhidao constructions. Chin. Lang. 4, 291-302.

Tao, J. (2001). The Study Of The Prosodic Model For Chinese Text To Speech System. $\mathrm{Ph} . \mathrm{D}$. dissertation, Tsinghua University.

Terken, J., and Swerts, M. (2002). Special issue on dialogue and prosody. Speech Commun. 36, 1-3. doi: 10.1016/S0167-6393(01)00021-8

Traugott, E. C. (1995). "The role of the development of disclosure markers in a theory of grammaticalization," in Paper presented at ICHL XII, Manchester.

Turner, M. (2002). An Analysis Of You Know In Face-To-Face Interaction. Ph.D. dissertation, University of Louisiana.

Vaissière, J. (1983). "Language independent prosodic features," in Prosody: Models and Measurements, eds A. Cutler and D. R. Ladd (Berlin: Springer Verlag), 53-66. doi: 10.1007/978-3-642-69103-4_5

Van Zyl, M., and Hanekom, J. J. (2012). When 'okay' is not okay: acoustic characteristics of single-word prosody conveying reluctance. J. Acoust. Soc. Am. 133, EL13-EL19. doi: 10.1121/1.4769399

Volín, J., Weingartová, L., and Niebuhr, O. (2016). The prosody of the Czech discourse marker 'Jasni': an analysis of forms and functions. Phonetica 73, 314-337. doi: $10.1159 / 000449002$

Wang, K. (2003). Sentence parallelism in English-Chinese/Chinese-English: a corpus-based investigation. Foreign Lang. Teach. Res. 6, 410-416.

Wang, L., and Liu, X. (2017). Constructing a model for the automatic identification of move structure in english research article abstracts. TEFLE. 45-50+64.

Wang, L., and Zhu, W. (2005). Study of the use of discourse markers in Chinese students' spoken English. Foreign Lang. Res. 3, 40-44.

Wang, M. (2011). Study Of The Prosodic Mode Of Chinese Spontaneous Speech. Guangzhou: Jinan University Press.

Wang, W. (2017). From a conditional marker to a discourse marker: the uses of dehua in natural Mandarin conversation. J. Pragmat. 117, 119-138. doi: 10.1016/j.pragma.2017.06.007

Ward, N. (2004). "Pragmatic functions of prosodic features in non-lexical utterances," in Proceedings of Speech Prosody 2004 (Japan: Nara), 325-328.

Ward, N. (2006). Non-lexical conversational sounds in American English. Pragmat. Cogn. 14, 129-182. doi: 10.1075/pc.14.1.08war

Ward, N., and Tsukahara, W. (2000). Prosodic features which cue back-channel responses in English and Japanese. J Pragmat. 32, 1177-1207. doi: 10.1016/ S0378-2166(99)00109-5
Wei, N. (2006). A corpus-based contrastive study of semantic prosodies in learner English. Foreign Lang. Res. 5, 50-54.

Wei, N. (2017). A corpus-based study of local grammar: background, approach, and characteristics. Foreign Lang. Stud. 1, 10-12.

Wichmann, A., Vandenbergen, A.-M., and Aijmer, K. (2010). Subjectification, intersubjectification and grammaticalization. Top. English Linguist. 66, 103-154. doi: 10.1515/9783110226102. 2.103

Winter, B., Brown, L., Idemaru, K., and Grawunder, S. (2013). Perceiving politeness from speech acoustics alone: a cross-linguistic study on Korean and English. J. Acoust. Soc. Am. 134, 5635-5641. doi: 10.1121/1.483 0871

$\mathrm{Wu}, \mathrm{F}$. (2005). Some typological features in the grammaticalization changes of Chinese. Chin. Lang. 6, 483-494.

$\mathrm{Wu}, \mathrm{Z}$. (2002). From traditional Chinese phonology to modern speech processing: realization of tone and intonation in standard Chinese. Lang. Teach. Linguist. Stud. 1, 11-14.

Xiong, Z. (2003). Prosodic Features And Communicative Functions Of Sentence Boundary In Spontaneous Speech. Ph.D. dissertation, Chinese Academy of Social Sciences.

Xiong, Z., and Lin, M. (2004). Prosodic features of "a" and their conversational communicative functions. Contemp. Linguist. 2, 116-127.

Xu, J. (1999). Study of Chinese Prosodic Features Based On Speech Corpus. Ph.D. dissertation, Chinese Academy of Social Sciences.

$\mathrm{Xu}, \mathrm{Y}$. (2004). Understanding tone from the perspective of production and perception. Lang. Linguist. 5, 757-797.

Xue, Y., and Liu, L. (2008). Linguistic markers for turn-holding and their contextual adaptability in Chinese TV interview talks. J. Sichuan Int. Stud. Univ. 6, 79-83.

Zhong, X., Wang, B., and Yang, Y. (2001). The perception of prosodic word stress in standard Chinese. Acta Psychol. Sin. 6, 481-488.

Conflict of Interest: The author declares that the research was conducted in the absence of any commercial or financial relationships that could be construed as a potential conflict of interest.

Publisher's Note: All claims expressed in this article are solely those of the authors and do not necessarily represent those of their affiliated organizations, or those of the publisher, the editors and the reviewers. Any product that may be evaluated in this article, or claim that may be made by its manufacturer, is not guaranteed or endorsed by the publisher.

Copyright ( $(2021$ Shan. This is an open-access article distributed under the terms of the Creative Commons Attribution License (CC BY). The use, distribution or reproduction in other forums is permitted, provided the original author(s) and the copyright owner(s) are credited and that the original publication in this journal is cited, in accordance with accepted academic practice. No use, distribution or reproduction is permitted which does not comply with these terms. 